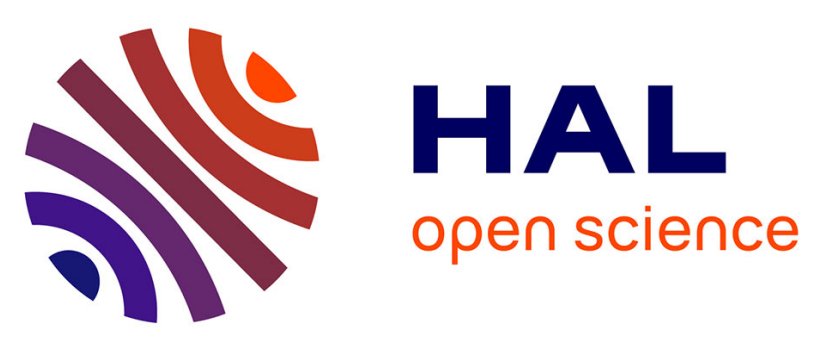

\title{
Calibrating a coupled SVAT - vegetation growth model with remotely sensed reflectance and surface temperature: a case study for the HAPEX - Sahel grassland sites
}

Pascale Cayrol, Laurent Kergoat, Sophie Moulin, Gérard Dedieu, Ghani Chehbouni

\section{To cite this version:}

Pascale Cayrol, Laurent Kergoat, Sophie Moulin, Gérard Dedieu, Ghani Chehbouni. Calibrating a coupled SVAT - vegetation growth model with remotely sensed reflectance and surface temperature: a case study for the HAPEX - Sahel grassland sites. Journal of Applied Meteorology, 2000, 39 (12), pp.2452-2472. 10.1175/1520-0450(2000)0392.0.CO;2 . hal-02699213

\section{HAL Id: hal-02699213 https://hal.inrae.fr/hal-02699213}

Submitted on 1 Jun 2020

HAL is a multi-disciplinary open access archive for the deposit and dissemination of scientific research documents, whether they are published or not. The documents may come from teaching and research institutions in France or abroad, or from public or private research centers.
L'archive ouverte pluridisciplinaire HAL, est destinée au dépôt et à la diffusion de documents scientifiques de niveau recherche, publiés ou non, émanant des établissements d'enseignement et de recherche français ou étrangers, des laboratoires publics ou privés. 


\title{
Calibrating a Coupled SVAT-Vegetation Growth Model with Remotely Sensed Reflectance and Surface Temperature- A Case Study for the HAPEX-Sahel Grassland Sites
}

\author{
P. CAYROL \\ CNRS/CNES/UPS, Centre d'Etude Spatiale de la Biosphere, Toulouse, France \\ L. KERGOAT \\ CNRS/UPS, Laboratoire d'Ecologie Terrestre, Toulouse, France \\ S. Moulin And G. Dedieu \\ CNRS/CNES/UPS, Centre d'Etude Spatiale de la Biosphere, Toulouse, France
}

A. Chehbouni

IRD/IMADES, Institut de Recherche pour le Developpement, Hermosillo, Mexico

(Manuscript received 30 August 1999, in final form 7 February 2000)

\begin{abstract}
Models simulating the seasonal growth of vegetation have been recently coupled to soil-vegetation-atmosphere transfer schemes (SVATS). Such coupled vegetation-SVATS models (V-S) account for changes of the vegetation leaf area index (LAI) over time. One problem faced by V-S models is the high number of parameters that are required to simulate different sites or large areas. Therefore, efficient calibration procedures are needed. This study describes an attempt to calibrate a V-S model with satellite [Advanced Very High Resolution Radiometer (AVHRR)] data in the shortwave and longwave domains. A V-S model is described using ground data collected over three semiarid grassland sites during the Hydrological Atmospheric Pilot Experiment (HAPEX)-Sahel experiment. The effect of calibrating model parameters with time series of normalized difference vegetation index (NDVI) and thermal infrared (TIR) data is assessed by examining the simulated latent heat flux (LE) and LAI for a suite of calibration experiments. A sensitivity analysis showed that the parameters related to plant growth vigor and to soil evaporative resistance were the best candidates for calibration. The NDVI and TIR time series were used to calibrate these parameters, both independently and simultaneously, to assess their synergy. Ground-based, airborne, and satellite sensor (AVHRR) data were successively investigated. Both airborne and AVHRR NDVI data could be used to constrain the vegetation growth vigor. These calibrations significantly improved the simulation of the LAI and LE (rmse decreased by $21 \%$ for LE), and the site-to-site variability was greatly enhanced. The soil resistance could also be calibrated with ground-based TIR data, but the effect on the simulated variables was small. Although both NDVI and ground-based TIR data were suitable to constrain the V-S model, the synergy between the two wavelengths was not clearly established. Last, satellite TIR data from the AVHRR proved unsuitable for model calibration. Indeed, the AVHRR surface temperature values were systematically lower than both ground-based data and model outputs. The authors conclude that the calibration of a vegetation-SVAT model with shortwave AVHRR time series can be used to scale the energy and water fluxes up to the regional scale.
\end{abstract}

\section{Introduction}

The role of vegetation canopies in regulating biosphere-atmosphere interactions has long been recognized (e.g., Monteith 1975; Sellers 1986; Pielke and Avissar 1990). This important role has led to the de-

Corresponding author address: Pascale Cayrol, CESBIO, 18 Av. E. Belin, BPI 2801, 31401 Toulouse Cedex 4, France.

E-mail: pascale.cayrol@cesbio.cnes.fr velopment of the soil-vegetation-atmosphere-transfer schemes (SVATS), which solve the surface energy and water budgets in such a way that the contribution of the vegetation is explicitly described (Shuttleworth and Wallace 1985; Taconet et al. 1986; Noilhan and Planton 1989; Shuttleworth and Gurney 1990; Braud et al. 1997; Flerchinger et al. 1998 among others). Additionally, it becomes increasingly apparent that accurate representation of heat and mass transport between the land and the atmosphere requires that the dynamics of the vegetation is taken into account. Seasonal and interannual 
climate or hydrological cycle simulations are good examples of this requirement (e.g., Dirmeyer 1994). Indeed, at these time scales, the plant canopies may display drastic changes; within a few weeks, bare soil may turn into fully developed grassland, which will have a great impact on the turbulent fluxes as well as on the partition of the precipitation between runoff and infiltration. During the last decades, vegetation models have been designed to simulate the seasonal and interannual variability in plant structure and function. Some of these vegetation models are now being coupled to SVATS (e.g., Lo Seen et al. 1997; Calvet et el. 1998b) and even to atmospheric models [to a mesoscale model (Pielke et al. 1997), or a general circulation model (Dickinson et al. 1998)]. This coupling may provide much needed insights on the interactions between terrestrial ecosystems and atmosphere. The drawback, however, is the tremendous number of parameters that will be required to calibrate such models. In fact, both soil and vegetation characteristics exhibit large spatial and temporal variability. Therefore, effective and time-efficient calibration procedures need to be used (Gupta et al. 1998).

Remotely sensed data, by providing frequent observations at different spatial scales, have been used increasingly to validate or to control the model's simulations. This is performed either through a periodic update of the model state variables, or through reinitialization of the model, or by calibrating some of the model parameters. Some of these techniques are referred to as data assimilation. Assimilation of satellite observations is widely used in atmospheric and oceanographic sciences, and is currently being investigated for modeling surface processes (e.g., Entekhabi et al. 1994; Calvet et al. 1998a; Houser et al. 1998; Jones et al. 1998b; Olioso et al. 1999).

Previous works have shown that the visible and nearinfrared reflectances, acquired by the earth observing satellites, can be used to calibrate vegetation growth models (Maas 1991; Bouman 1992; Delécolle et al. 1992; Kergoat et al. 1995a; Moulin et al. 1998). Indeed, surface reflectances in these wavelengths have long been related to the amount of green tissue (Tucker 1979) and have proved useful to monitor the seasonal evolution of plant canopies. They can therefore be used to constrain a prognostic vegetation model, using, for example, the Leaf Area Index (LAI) as a control variable. However, most of the models calibrated with remotely sensed reflectance were dedicated to crops.

Similarly, thermal infrared and microwave emissions have long been related to surface temperature and soil moisture respectively. Some studies have shown that these data could be used to calibrate SVAT models (Olioso et al. 1999). Taconet et al. (1986) used Advanced Very High Resolution Radiometer (AVHRR) surface temperature and an SVAT model to calibrate the canopy resistance to water diffusion and to infer the surface fluxes and soil water content. Most of these SVAT model calibrations were feasibility studies that were mainly focused on crops or bare soil (Camillo et al. 1986b; Burke et al. 1997; Mattikalli et al. 1998). With the exception of Taconet et al. (1986) and Mattikali et al. (1998), most of the results were obtained with ground-based measurements, as opposed to satellite data. Furthermore, most of these studies considered static vegetation and did not address the impact of vegetation temporal development.

The objectives of this paper are twofold: 1) to present a coupled SVAT (Lo Seen et al. 1997) and vegetation growth model (Kergoat et al. 1995b) and 2) to evaluate the impact of the calibration of the model with time series of AVHRR surface reflectance and temperature on the model performance. Data were collected over semiarid grassland sites during the Hydrological Atmospheric Pilot Experiment (HAPEX)-Sahel experiment. This paper is organized as follows. Section 2 describes the site and data. In section 3 , we introduce a description of the coupled vegetation-SVAT model. Section 4 presents a sensitivity analysis of the vegetation-SVAT model to different parameters values and also describes the calibration technique. In section 5 , we evaluate the impact of the calibration with shortwavelength satellite observations on the vegetation growth, and the impact of the calibration with longwave observations on the SVAT model. Last, the potential and the limitations of this approach are discussed in section 6 .

\section{Sites and data \\ a. Description of the site}

The HAPEX-Sahel experiment was conducted in Niger during the 1992 rainy season. Measurements of both atmospheric and surface processes were performed in a $1^{\circ} \times 1^{\circ}$ area. Detailed field measurements were concentrated in three sites: Central East Site (CES) $\left(13^{\circ} 33^{\prime} 37^{\prime \prime} \mathrm{N}, 2^{\circ} 40^{\prime} 44^{\prime \prime} \mathrm{E}\right)$, Central West Site (CWS) $\left(13^{\circ} 32^{\prime} 42^{\prime \prime} \mathrm{N}, 2^{\circ} 30^{\prime} 54^{\prime \prime} \mathrm{E}\right)$, and Southern Site (SS) $\left(13^{\circ} 14^{\prime} 37^{\prime \prime} \mathrm{N}, 2^{\circ} 14^{\prime} 43^{\prime \prime} \mathrm{E}\right)$, which were divided into several subsites [see Goutorbe et al. (1994) for details]. Tiger bush, fallow fields, and crops (mainly millet) covered the $1^{\circ}$ square area. The fallow fields had not been cropped for several years (2-7 yr), allowing a "natural" vegetation to regenerate. This consists of a layer of annual forbs and grasses, which we call grassland in the following. Grasslands represent 39\% of the total area (d'Herbes and Valentin 1997). The Sahel region is characterized by a single and short annual rainy season extending from June to September with a maximum of precipitation in August. As a result, the grass layer developed rapidly during August and September and reached an LAI of about 1 by the end of the season.

\section{b. Ground and airborne measurements}

The energy balance components, some biological variables (biomass, LAI) and ground or airborne radiative 

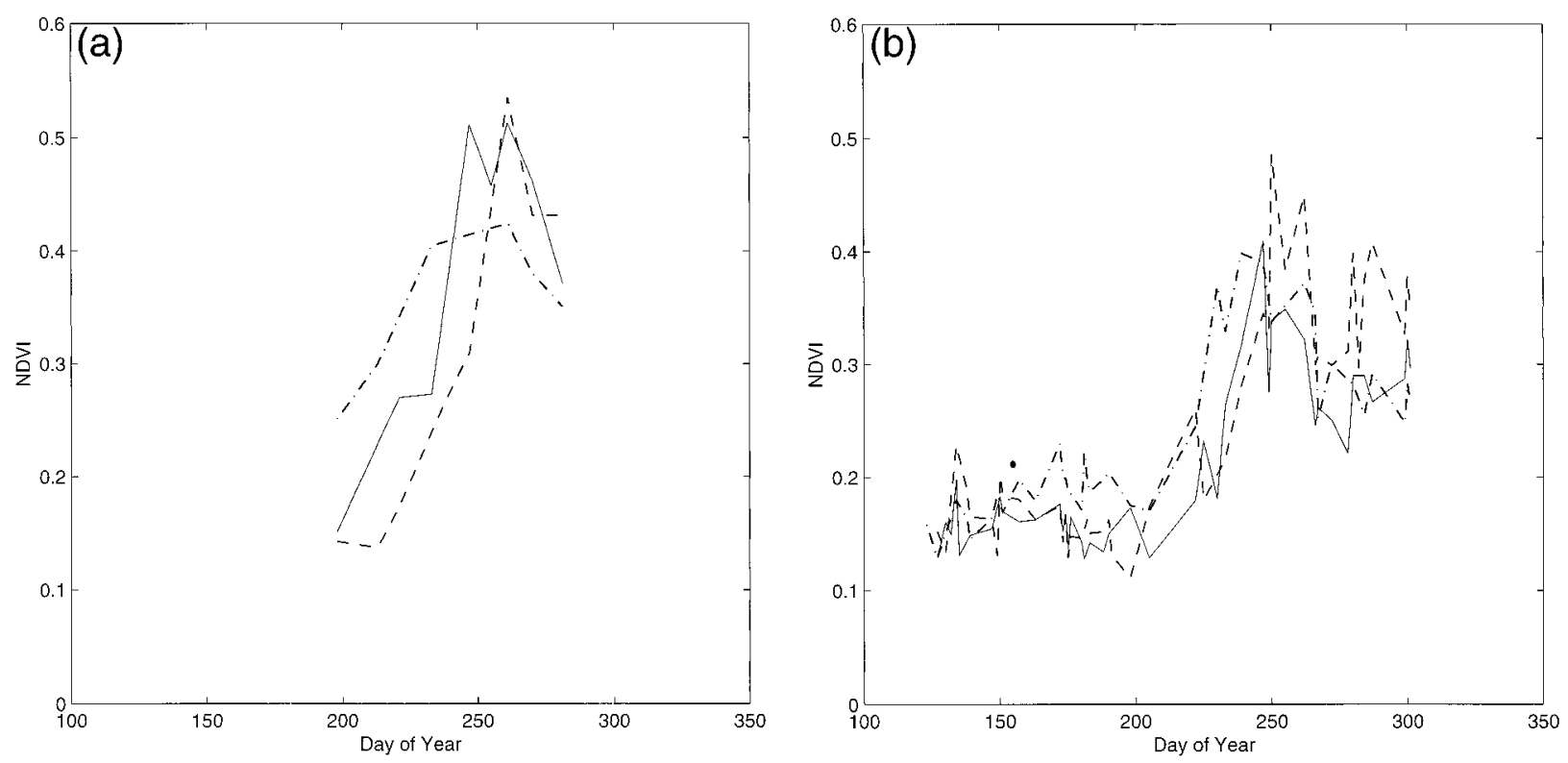

FIG. 1. (a) NDVI profile of the grassland component obtained for airborne NDVI on CES (solid line) and on CWS (dashed line), Also shown is SS (dash-dot line), which represents NDVI profile of the grass-shrub components. (b) NDVI profiles of the grassland component obtained from unmixing of the AVHRR signal on CES (solid), on CWS (dashed), and SS (dash-dot).

measurements were collected for the three supersites, along with meteorological data. For each supersite, the rainfall data coming from the nearest rain gauge of the Estimation des Precipitations par Satellite network were used (Lebel et al. 1992). We computed hourly values from the 20-min meteorological and energy flux measurements. LAI values on CES (Monteny et al. 1997) were deduced from biomass measurements. On CWS, the values of LAI are based on growth curves fitted to the measured data (Prince et al. 1995), and on SS, the LAI were measured by Levy et al. (1997).

Three series of brightness temperatures (in the 8-14$\mu \mathrm{m}$ domain) were acquired over grassland and one series was acquired over bare soil on SS, whereas one series of measurements was performed on CES. In the following, surface temperature will refer to a temperature that has been corrected for surface emissivity, as opposed to brightness temperature, for which an emissivity of 1 is assumed. In general, the term radiative temperature is used for both surface and brightness temperatures. Reflectances were measured on the grassland subsites of CES and CWS. For the SS, reflectances were measured over a mixture of grasses and shrubs as opposed to LAI and temperature measurements, which were acquired over grasses only. This area is called the grass-shrub subsite. The measurements were acquired with an Exotech, Inc., $100 \mathrm{BX}$ radiometer operated from a light aircraft in the red $[R,(0.63-0.69 \mu \mathrm{m})]$ and nearinfrared [NIR, $(0.76-0.90 \mu \mathrm{m})]$ Landsat TM (Thematic Mapper) wavebands (Hanan et al. 1997). The normalized difference vegetation index (NDVI) (Rouse et al. 1974) was computed from red and near-infrared reflectances as NDVI $=(\mathrm{NIR}-R) /(\mathrm{NIR}+R)$.

\section{c. Satellite measurements}

AVHRR data (1.1-km resolution) were acquired from the afternoon NOAA-11 satellite overpass, around 1400 LT, from May to October 1992. The red and near-infrared data were partly corrected for atmospheric effects (water vapor, ozone, and Rayleigh diffusion) (Rahman and Dedieu 1994). In this semiarid region, the vegetation cover is very heterogeneous and the AVHRR pixel is a so-called mixed pixel. A linear unmixing algorithm was applied to the AVHRR dataset in order to retrieve the pure grassland signature for the three sites (e.g., Ouaidrari et al. 1996). The NDVI temporal profiles of the different components on CES, CWS, and SS were compared to the airborne NDVI (Fig. 1a) acquired over the same sites (Hanan et al. 1997). The NDVI profiles of grassland on the three supersites match the unmixed AVHRR profiles (Fig. 1b) reasonably well. They show consistent patterns and timing, although the spectral bands and instrument field of view are different. The AVHRR NDVI time-series exhibit larger day-to-day variations. The drops are most probably due to residual noises caused by the atmosphere (e.g., pixel contaminated by small clouds, aerosols). When compared with the original AVHRR mixed pixel, the unmixed NDVI is much higher for grasslands and much lower for millet crop (Fig. 2).

Surface temperature measurements were derived from AVHRR thermal infrared (TIR) channels 4 (10.3-11.3 $\mu \mathrm{m})$ and $5(11.5-12.5 \mu \mathrm{m})$, using a split window algorithm (Kerr et al. 1992, 1993). This split window algorithm provides a surface temperature, as opposed to a brightness temperature (emissivity is 1). The ac- 


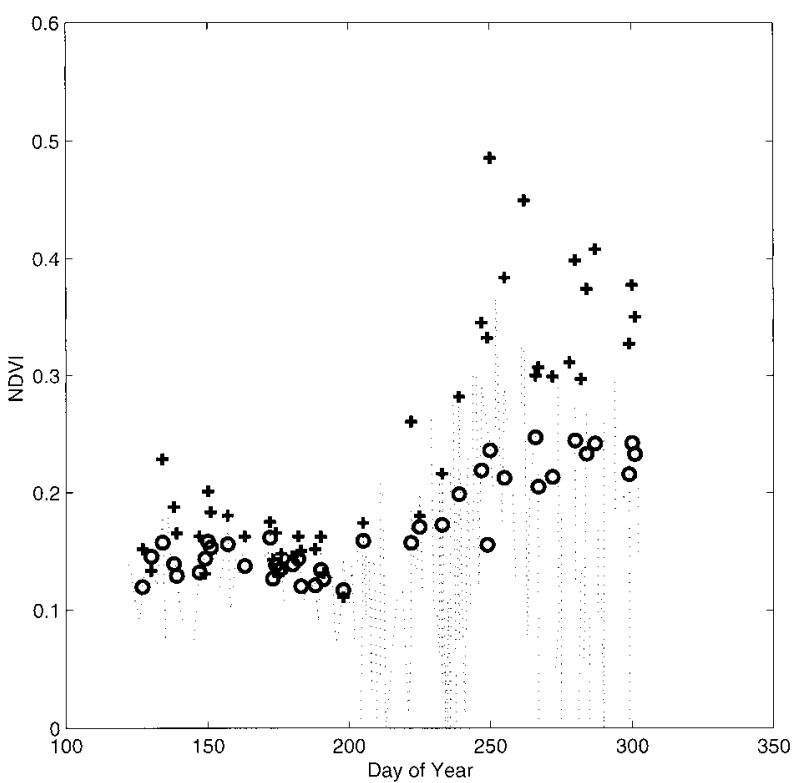

FIG. 2. NDVI profiles of the pure grassland (cross) and pure millet (circle) components resulting from the unmixing process of the AVHRR signal. The dotted line represents the NDVI over the mixed pixel, before cloud screening. The grassland NDVI is significantly higher than the mixed-pixel NDVI, whereas the millet NDVI is lower.

curacy of the split window technique will be discussed in section 6 .

\section{Model description}

A detailed description of the coupled vegetationSVAT model can be found in appendix A and an extensive list of symbols is given in appendix B.

The coupled vegetation-SVAT model (hereinafter V-S model) can be schematically presented as two interacting submodels. Figure 3 shows the state variables, the main fluxes and some of the model linkages. The coupling of the vegetation growth model with the water and energy budget model is performed by exchanging the relevant variables between the models. The vegetation growth model provides the LAI, which is used by the SVAT in the computation of the energy partitioning between the soil and the vegetation as well as in the parameterization of turbulent transport and evapotranspiration. The SVAT model updates the soil water content in the root zone, which, in turn, has an impact on plant physiology through the canopy resistance $\left(r_{c}\right)$, and also tissue mortality rate. The canopy resistance is used by both submodels, to compute either transpiration or photosynthesis. The soil and the vegetation are considered as two different sources of latent and sensible heat fluxes (Shuttleworth and Wallace 1985). The incoming solar energy is partitioned between bare soil and vegetation through a screen factor. The scheme uses the force and restore model for soil heat and water content (Deardoff 1978). The model is controlled by meteorological forcing such as air temperature, air humidity, wind speed, precipitation, and solar radiation; soil parameters such as soil texture (percent clay, percent sand), soil thermal and hydraulic properties, root depth, and vegetation parameters such as specific leaf area (maximum rate of photosynthesis).

\section{Methodology \\ a. Predicting the radiative variables}

\section{1) SurfaCE REFLECTANCE}

Visible and near infrared reflectances were estimated with the SAIL model, which is used to process the output (LAI) from the V-S model. Scattering by Arbitrarily Inclined Leaves (SAIL) (Verhoef 1984) is a turbid medium reflectance model, which considers a homogeneous canopy and uses the Kubelka-Munk approximation to the radiative transfer equation (Goel 1988). The model describes the dependence of spectral reflectance on LAI, leaf and soil optical properties, leaf angle distribution, acquisition geometry, and the diffuse part of the incoming solar radiation. The ratio between leaf size and vegetation height accounts for the hot spot, which represents the local maximum of reflectance when the solar illumination and viewing observation angles coincide (Kuusk 1991). Other input parameters come from literature (see Table 1), except for the geometric conditions, which correspond to the acquisition configurations. The simulated red and near-infrared reflectances were combined to compute NDVI in either the airborne or satellite acquisition conditions.

\section{2) RADiATIVE TEMPERATURE}

The composite radiometric temperature of the surface (i.e., the radiative temperature, $T_{r}$ ) was computed from canopy and ground temperatures, $T_{c}$ and $T_{g}$, predicted by the SVAT, by the following approximate expression:

$$
T_{r}=\left[\sigma_{f} \varepsilon_{c} T_{c}^{4}+\left(1-\sigma_{f}\right) \varepsilon_{g} T_{g}^{4}\right]^{1 / 4},
$$

where $\varepsilon_{g}$ and $\varepsilon_{c}$ are ground and canopy emissivities, respectively, and $\sigma_{f}$ is defined as a screen factor. The radiative temperature defined in Eq. (1) corresponds to a brightness temperature.

\section{b. Model sensitivity tests}

Because the objective of this study is to use short- and longwave remotely sensed data to calibrate some parameters of the vegetation growth-SVAT model, the first step consists of identifying the relevant parameters. Here we are specifically interested in parameters that (a) are poorly known and may present large spatial variability, (b) have an important impact on the model's outputs, and (c) significantly affect the short- and longwave radiative transfer simulations.

Because both the SVAT and the vegetation submodels require a significant number of input parameters, we first 


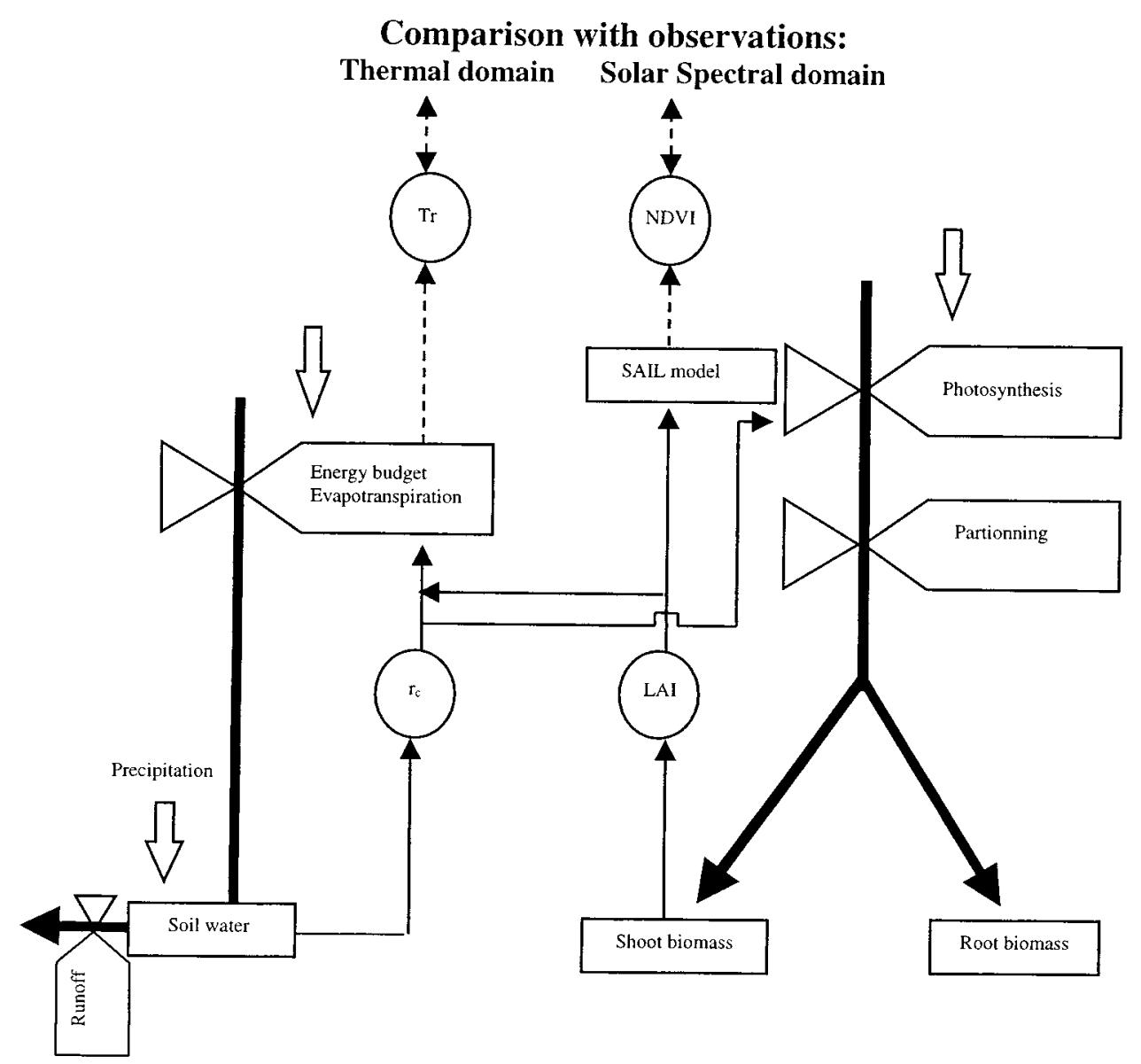

FIG. 3. Coupled vegetation growth and energy-water budget models (V-S). The large bold arrow indicates carbon, water, and energy fluxes. The state variables are the carbon contents in the shoots and the roots, and the water content of the soil. The thin arrow represents some of the model links. The dashed-line arrow shows how radiative properties are derived from model variables. The outlined arrow represents the meteorological forcing (air temperature, relative humidity, wind speed, solar radiation, and precipitation).

performed a sensitivity analysis to identify the best candidates for the calibration. Except for the specific leaf area and maximum leaf stomatal conductance [taken from ground measurements [(Hanan et al. 1997)] the model parameters were derived from literature review (Körner 1994; Amthor 1989; see also Kergoat et al. 1995b; Kergoat 1998). Rough estimates of the potential errors were determined for every parameter (from $1 \%$ to $25 \%$, see Table 2). Each parameter was varied independently. The impact on the model outputs was assessed from the variations of LAI compared to the LAI at peak biomass [day of year (DoY) 270]), and from the variations of latent heat flux and surface temperature at 1400 LT averaged over 31 days (255-285 DoY). The results were ranked by decreasing LAI sensitivity (Table 2). The parameters showing an LAI variation lower than $0.2 \%$ are not shown, and are considered unsuitable for calibration. Table 2 clearly shows that the vegetation development is highly sensitive to several parameters, since there is a strong positive feedback loop between the LAI and the canopy productivity. Moreover, an increase in LAI is generally associated with a decrease of the radiative temperature and an increase of the latent heat flux. As a result, the surface temperature proved to be very sensitive to the same "vegetation-related" parameters, in addition to the expected "water and energy-related" parameters, like the soil resistance, the vegetation height and the soil emissivity. This sensitivity study highlights two main conclusions: (i) The vegetation submodel is sensitive to several parameters, which have similar or nearly similar effects; and (ii) the radiative temperature is equally sensitive to the vegetation parameters and to the water and energy parameters (Table 2).

\section{c. Calibration technique with short-wave and long- wave measurements}

\section{1) The methodology of Calibration}

The principle of the calibration technique is to derive some of the model parameters from remotely sensed 
TABLE 1. Specification of the SAIL model input parameters. Soil and canopy optical parameters were prescribed for visible $(\lambda 1)$ and near infrared ( $\lambda 2)$ after Van Leuwen et al. (1997). Leaf properties are computed as the average of green and yellow leaf properties, weighted by the biomass/phytomass and necromass/phytomass ratios. The view and solar angles for the AVHRR conditions vary for every pixel and are found in the HSIS database (Kerr et al. 1993).

Canopy structure parameters
LAI

As predicted by the coupled model

Hot spot parameter* 0.01

Leaf angle distribution

Spherical $\left(\right.$ mean leaf angle $\left.=57.30^{\circ}\right)$

\begin{tabular}{|c|c|c|c|c|}
\hline & \multicolumn{2}{|c|}{ TM wavebands } & \multicolumn{2}{|c|}{$\begin{array}{c}\text { AVHRR } \\
\text { wavebands }\end{array}$} \\
\hline & $\lambda 1$ & $\lambda 2$ & $\lambda 1$ & $\lambda 2$ \\
\hline \multicolumn{5}{|c|}{ Canopy and soil optical properties } \\
\hline Soil reflectance & 0.30 & 0.40 & 0.28 & 0.40 \\
\hline Green leaf reflectance & 0.12 & 0.48 & 0.16 & 0.43 \\
\hline Yellow leaf reflectance & 0.45 & 0.52 & 0.45 & 0.50 \\
\hline Green leaf transmittance & 0.06 & 0.37 & 0.03 & 0.32 \\
\hline Yellow leaf transmittance & 0.12 & 0.10 & 0.12 & 0.10 \\
\hline \multicolumn{5}{|c|}{ Illumination and view conditions } \\
\hline \multirow[t]{2}{*}{$\begin{array}{l}\text { Diffuse fraction of } \\
\text { solar radiation }\end{array}$} & $20 \%$ & & & \\
\hline & $\begin{array}{l}\text { tech } \\
\text { itions }\end{array}$ & \multicolumn{3}{|c|}{$\begin{array}{l}\text { AVHRR } \\
\text { conditions }\end{array}$} \\
\hline View zenith angles & $0^{\circ}$ & \multicolumn{3}{|l|}{ Varying } \\
\hline Solar zenith angles & $32.4^{\circ}$ & \multicolumn{3}{|c|}{ Varying } \\
\hline Relative azimuth & $20^{\circ}$ & \multicolumn{3}{|c|}{$\varphi_{\text {solar }}-\varphi_{\text {sensor }} * *$, varying } \\
\hline
\end{tabular}

* Ratio between leaf size and vegetation height.

$* * \varphi$ is for azimuth. data in order to calibrate the model wherever and whenever ground or literature estimates are missing or inaccurate. One originality of this study consists of performing the calibration with measurements acquired in two different wavelength domains. The model-derived radiative properties are compared to shortwave measurements via NDVI, and to longwave measurements through the radiative temperature (Fig. 3).

The calibration of the coupled model was based on an iterative procedure, which compared the time series of simulated variables $\left(Y_{\text {sim }}\right)$ and of observed variables $\left(Y_{\text {obs }}\right)$ and minimized their difference by adjusting some chosen parameters. The optimization was obtained by minimizing the root-mean-square error (rmse), which characterizes the distance between observed and simulated variables, according to

$$
\text { rmse }=\left[\frac{1}{N-2} \sum_{i=1}^{N}\left(Y_{\mathrm{obs}}^{i}-Y_{\mathrm{sim}}^{i}\right)^{2}\right]^{1 / 2},
$$

where $N$ is the number of observations. The downhill simplex method (Matlab, from The MathWorks, Inc.) was used for the optimization. Least squares methods are popular for solving inverse problems and confidence intervals can easily be computed. At this stage, model or observations errors are not specifically addressed. In the case of shortwave data assimilation, the simulated variable $Y$ was the NDVI, whereas the simulated variable was the radiative temperature for the calibration with the longwave data. We choose here a "model to satellite" approach (Hollingsworth 1990), which consists of predicting NDVI and radiative temperature from the model state variables (e.g., LAI). An alternative would be to infer LAI from NDVI data, through inver-

TABLE 2. Sensitivity tests. Variations in LAI, in radiative temperature $\left(T_{r}\right)$, and in latent heat flux (LE) as simulated by the model for different values of the input parameters. The third column corresponds to a priori values parameters (simulation S0). The results were ranked by decreasing LAI sensitivity (fifth column). Note that the sensitivity bias is applied to the soil resistance $r_{\mathrm{ss}}$ and to canopy height, and not independently to the different parameters used in these equations. For the soil resistance, this is equivalent to applying the same sensitivity bias to both parameters $a$ and $b$ at the same time.

\begin{tabular}{|c|c|c|c|c|c|c|}
\hline Parameters & Units & $\begin{array}{l}\text { A priori } \\
\text { values }\end{array}$ & $\begin{array}{c}\text { A priori error } \\
\Theta_{\mathrm{i}}(\%)\end{array}$ & $\begin{array}{c}\text { Variation in LAI } \\
(\%)\end{array}$ & $\begin{array}{l}\text { Variation in } T_{r} \\
\quad\left({ }^{\circ} \mathrm{C}\right)\end{array}$ & $\begin{array}{l}\text { Variation in LE } \\
\quad\left(\mathrm{W} \mathrm{m}^{-2}\right)\end{array}$ \\
\hline $\mathrm{SLA}_{0}$ & $\mathrm{mg}^{2} \mathrm{kgC}^{-1}$ & 23 & 15 & 45 & -2.2 & 11.8 \\
\hline$a_{5}=0$ & Unitless & 0.56 & 10 & 22 & -1.3 & 4.25 \\
\hline IC & $\mathrm{kgC} \mathrm{m}^{-2}$ & 0.00369 & 20 & 11 & -0.71 & 2.58 \\
\hline$\alpha$ & $\mathrm{molCO}_{2} \mathrm{~mol}(\mathrm{PAR})^{-1}$ & 0.04 & 10 & 9 & -0.4 & 1.6 \\
\hline$a, b$ or $r_{\mathrm{ss}}^{*}$ & $\mathrm{~s} \mathrm{~m}^{-1}\left(\mathrm{~m}^{3} \mathrm{~m}^{-3}\right)^{-1}, \mathrm{~s} \mathrm{~m}^{-1}$ & 7000,1520 & 15 & 8.5 & 0.93 & -21.6 \\
\hline$g_{s}$ & $\mathrm{~g} \mathrm{~g}^{-1}$ & 0.6 & 10 & -7.5 & 0.12 & -1.8 \\
\hline$d_{2}^{s}$ & $\mathrm{~cm}$ & 60 & 15 & -7.5 & 0.51 & 1.92 \\
\hline Clay & $\%$ & 6 & 15 & -5 & -0.05 & 4.7 \\
\hline$P_{\max }$ & $\mu \mathrm{molCO}_{2} \mathrm{~m}^{-2} \mathrm{~s}^{-1}$ & 30 & 5 & 3.2 & -0.28 & 0.97 \\
\hline Sand & $\%$ & 85 & 15 & 3.9 & -0.8 & 7.16 \\
\hline$g_{s \max }$ & $\mathrm{m} \mathrm{s}^{-1}$ & 0.0078 & 10 & 3 & -0.26 & 5.2 \\
\hline$s_{s 0}$ & day $^{-1}$ & 0.01 & 15 & -1.5 & 0.003 & -0.21 \\
\hline$m_{s 0}$ & day $^{-1}$ & 0.0003 & 15 & -1.1 & 0.06 & -0.25 \\
\hline Height** & $\mathrm{cm}$ & $\mathrm{F}\left(\mathrm{M}_{\mathrm{s}}\right)$ & 25 & 1.1 & -0.91 & -6.5 \\
\hline$\epsilon_{g}$ & Unitless & 0.96 & 1 & 0.4 & 1.1 & -0.98 \\
\hline Trans & $\mathrm{kgC} \mathrm{m}^{-2}$ day $^{-1}$ & 0.0004 & 15 & -0.2 & 0.014 & -0.045 \\
\hline
\end{tabular}

* See appendix $\mathrm{C}$ for the equation.

** See appendix B for the equation. 
TABLE 3. Impact of the different calibration schemes on the radiative temperature $\left(T_{r}\right)$ and latent heat flux (LE) for CES and SS. The rmse is in watts per meter squared for latent heat flux and in kelvins for radiative temperature. $R^{2}$ is the Nash-Sutcliffe efficiency. ${ }^{*}$ Here $V$ is the vigor parameter, and $a / b$ corresponds to the parameters $a$ and $b$ of the soil resistance parameterization.

\begin{tabular}{|c|c|c|c|c|c|c|c|c|c|c|c|}
\hline \multirow{3}{*}{$\begin{array}{l}\text { Simu- } \\
\text { lations }\end{array}$} & \multirow[b]{3}{*}{ Calibration } & \multicolumn{6}{|c|}{ CE site } & \multirow{2}{*}{\multicolumn{4}{|c|}{ S site }} \\
\hline & & & & & & LE & & & & & \\
\hline & & $V$ & $a / b$ & $T_{r}$ rmse & $T_{r} R^{2}$ & rmse & LE $R^{2}$ & $V$ & $a / b$ & $T_{r}$ rmse & $T_{r} R^{2}$ \\
\hline S0 & No & 0 & $7000 / 1520$ & 4.92 & 0.44 & 75 & 0.42 & 0 & $7000 / 1520$ & 3.1 & 0.67 \\
\hline S1 & V/airborne NDVI & 1.34 & $7000 / 1520$ & 4.2 & 0.6 & 63 & 0.45 & 0.05 & $7000 / 1520$ & 3.1 & 0.68 \\
\hline S2 & V/satellite NDVI & 0.87 & $7000 / 1520$ & 4.26 & 0.6 & 60 & 0.5 & -0.42 & $7000 / 1520$ & 3.2 & 0.65 \\
\hline S3 & $a, b /$ ground TIR & 0 & $3720 / 898$ & 4 & 0.62 & 89 & 0.5 & - & - & - & - \\
\hline S4 & $\begin{array}{l}\text { V/airborne NDVI } \\
\quad+a, b / \text { ground TIR }\end{array}$ & 1.34 & $6021 / 1330$ & 4.1 & 0.59 & 62 & 0.48 & 0.05 & $7730 / 1609$ & 3 & 0.69 \\
\hline S5 & V/ground TIR & 1.2 & $7000 / 1520$ & 4.2 & 0.6 & 61 & 0.48 & - & - & - & - \\
\hline
\end{tabular}

sion of the SAIL scheme and then to compare inferred LAI and modeled LAI to calibrate the V-S model. This would be a "satellite to model" approach. However, the LAI inversion is likely to add significant errors, because of the inversion lack of robustness and sensitivity to outliers in the remote sensing data.

\section{2) CHOICE OF THE PARAMETERS FOR THE CALIBRATION WITH NDVI}

The model sensitivity tests have shown that several vegetation model parameters are good candidates for calibration: namely the initial specific leaf area $\left(\mathrm{SLA}_{0}\right)$, the shoots allocation $\left(a_{s}\right)$ the initial carbon storage (IC), the quantum yield $(\alpha)$, and the growth respiration coefficient $\left(g_{s}\right)$. The sensitivity tests also suggest that these parameters cannot be calibrated separately because they impact the LAI in similar ways (not shown). Consequently, even a large number of NDVI observations does not allow to infer their respective roles. A reasonable solution would be to lump these parameters into a single parameter, which could then be calibrated. However, because of the model structure, these five parameters cannot be replaced by a lumped parameter. Here we propose to apply a single calibration coefficient to these five parameters. The objective was to distribute the correction between the five parameters, according to their a priori errors. The set of calibrated parameters $\left(\mathrm{Par}_{i}\right)$ can be written as follows:

$$
\operatorname{Par}_{i}=\operatorname{Par}_{i}^{\mathrm{ref}}\left(1+\delta_{i} V \Theta_{i}\right) \text { with } i=1 \text { to } 5 \text {, }
$$

where $\operatorname{Par}_{i}^{\text {ref }}$ are the reference values of the parameters, $V$ is the calibration factor, and $\Theta_{i}$ is the a priori uncertainty of each parameter (Table 2). The $\delta_{i}$ factor is set to 1 or -1 depending on whether the parameter has a positive or negative impact on plant growth. When $V$ equals 1 or -1 , the parameters reach the extreme values used in the sensitivity analysis. The $V$ coefficient can be seen as a measure of the "vigor" of the vegetation.
High positive $V$ would increase plant growth, whereas negative $V$ would decrease it.

\section{3) CHOICE OF THE PARAMETERS FOR THE} CALIBRATION WITH THERMAL INFRARED (TIR)

According to the sensitivity tests, the variations of the soil resistance coefficients (appendix C), the vegetation height and the soil emissivity have the strongest impact on the radiative temperature simulation (Table $2)$. The soil resistance, $r_{\mathrm{ss}}$, which depends on the soil hydraulic properties, is expected to display a high spatial variability even at the regional scale. In consequence, the minimization of rmse [Eq. (2)] was performed by tuning the soil resistance coefficients $(a, b)$. The same relative correction is applied to $a$ and $b$ to keep the parameterization consistency, so that the calibration affects the soil resistance as a whole.

\section{4) Simulations AND CAlibration DESign}

A set of calibrations was performed to investigate in detail the relative interest of using short-wave and longwave data to calibrate the $\mathrm{V}-\mathrm{S}$ model. The reference simulations (S0) make use of the a priori parameters values given in Table 3 . For the $\mathrm{S} 1$ simulations, the plant vigor parameter $(V)$ was adjusted for each site to match the airborne NDVI data. For the S2 simulations plant vigor $V$ was calibrated using satellite NDVI data. The S3 simulation used only ground-based TIR data to calibrate the soil resistance parameters. The S4 simulations used airborne data to calibrate $V$ and then ground-based TIR data to calibrate the soil resistance parameters, whereas the S5 simulation, which will be discussed in the section 6 used ground-based TIR data to calibrate plant vigor parameters $(V)$. 


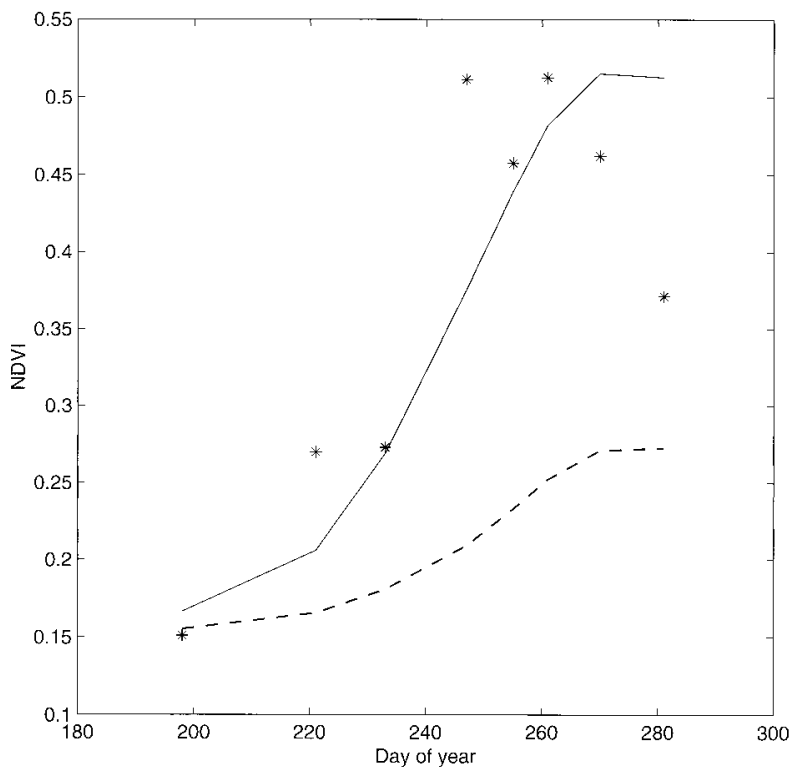

FIG. 4. Comparison of NDVI time-profile generated with the SAIL model and simulated LAI with airborne measurements (asterisk) over the CES grassland. The dashed line is the NDVI resulting from the reference $\mathrm{V}-\mathrm{S}$ simulation (simulation S0), solid line is the NDVI after calibration of the V-S model with airborne NDVI data (simulation S1).

\section{Results}

a. Results of the model calibration with airborne and satellite NDVI data

This section presents the results of the calibration of the $\mathrm{V}-\mathrm{S}$ model with NDVI time series. In a first step (simulations $\mathrm{S} 1$ ), the vigor parameter $(V)$ was adjusted to match airborne measurements collected over the three sites (shown in Fig. 1a). In a second step (simulations S2), the same parameter was adjusted to match the AVHRR NDVI time series (see Fig. 1b). The impact of the calibration on the model's results was evaluated with regards to NDVI, LAI, and latent heat flux.

The adjustment of the vigor parameter $V$ allows the modeled NDVI to fit the airborne and unmixed AVHRR observations over the three sites (see Figs. 4 and 5 for the CES and CWS, respectively, the SS is not shown). A slight discrepancy is observed after DoY 280 for the $\mathrm{CE}$ and $\mathrm{CW}$ sites. The modeled NDVI do not decrease

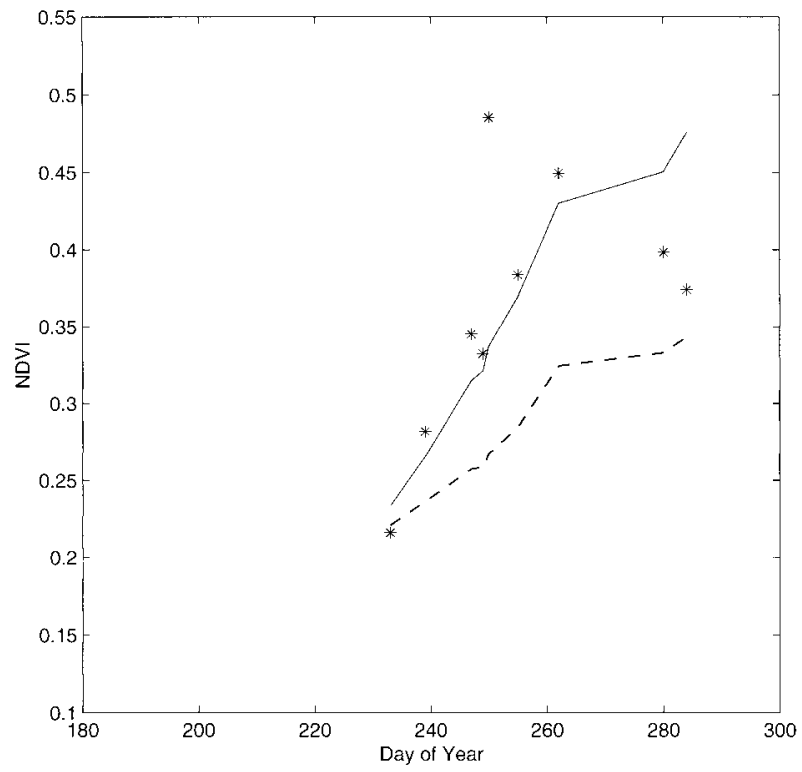

FIG. 5. Comparison of NDVI time-profile generated with the SAIL model and simulated LAI, with AVHRR unmixed NDVI (asterisk) on the CWS grassland site. The dashed line is the NDVI resulting from the reference V-S simulation (simulation S0), (solid line) is the NDVI after calibration of the V-S model with the AVHRR data (simulation S2).

as fast as the observed NDVI. Because this is the senescence period, this suggests that our treatment of dry and green tissue radiative properties may not be accurate enough and would benefit from future dedicated field studies. The resulting parameters are found in Table 4. The adjustment results in plausible parameter values. The confidence intervals at $95 \%$ on the retrieved parameter $(V)$ are reasonably well defined, except for the SS (simulation $\mathrm{S} 2, V=0.05$ ), for which the number of NDVI observations is only 4 . With both airborne and unmixed NDVI data, the calibrations increase plant vigor ( $V$ parameters $>0$ for simulations $\mathrm{S} 1$ and $\mathrm{S} 2$ ) for the CES and CWS, and decrease it slightly ( $V=-0.45$ for the simulation S2) for the SS. In terms of LAI, the calibrations lead to good agreement with the ground measurements over the three sites. Figures 6a,b,c show the a priori LAI (simulations S0) and the LAI obtained after calibration of the vigor parameter (simulations S1 and S2). In comparison with the reference simulations

TABLE 4. Detailed parameters values resulting from the calibration of the vegetation vigor for the S1 and S2 simulations. These simulations correspond to the calibration of the V-S model with airborne and AVHRR NDVI data on the CES, CWS, and SS, respectively. Here [] corresponds to the confidence interval at $95 \%$ on the vegetation vigor parameter.

\begin{tabular}{|c|c|c|c|c|c|c|c|c|}
\hline $\begin{array}{l}\text { Parame- } \\
\text { ters }\end{array}$ & $\begin{array}{l}\text { A priori } \\
\text { values }\end{array}$ & $\begin{array}{l}\text { A priori } \\
\text { error, } \\
\Theta_{i}(\%)\end{array}$ & $\begin{array}{c}\text { CES } \\
(\mathrm{S} 1, V=1.34) \\
{[0.941 .74]}\end{array}$ & $\begin{array}{c}\text { CES } \\
(\mathrm{S} 2, V=0.87) \\
{[0.611 .14]}\end{array}$ & $\begin{array}{c}\text { CWS } \\
(\mathrm{S} 1, V=1.2) \\
{\left[\begin{array}{ll}0.6 & 1.8\end{array}\right]}\end{array}$ & $\begin{array}{c}\text { CWS } \\
(\mathrm{S} 2, V=1.36) \\
{\left[\begin{array}{ll}0.9 & 1.76]\end{array}\right.}\end{array}$ & $\begin{array}{c}\mathrm{SS} \\
(\mathrm{S} 1, V=0.05) \\
{\left[\begin{array}{ll}-1.6 & 1.77\end{array}\right]}\end{array}$ & $\begin{array}{c}\mathrm{SS} \\
(\mathrm{S} 2, V=-0.42) \\
{\left[\begin{array}{ll}-1 & 0.44\end{array}\right]}\end{array}$ \\
\hline $\mathrm{SLA}_{0}$ & 23 & 15 & 27.6 & 26 & 27 & 27.7 & 23.2 & 21.6 \\
\hline$a_{s}$ & 0.56 & 10 & 0.63 & 0.61 & 0.63 & 0.63 & 0.56 & 0.54 \\
\hline IC & 0.00369 & 20 & 0.00467 & 0.00433 & 0.00457 & 0.00469 & 0.00372 & 0.00339 \\
\hline$\alpha$ & 0.04 & 10 & 0.045 & 0.043 & 0.045 & 0.045 & 0.04 & 0.036 \\
\hline$g_{s}$ & 0.6 & 10 & 0.52 & 0.55 & 0.53 & 0.52 & 0.6 & 0.62 \\
\hline
\end{tabular}



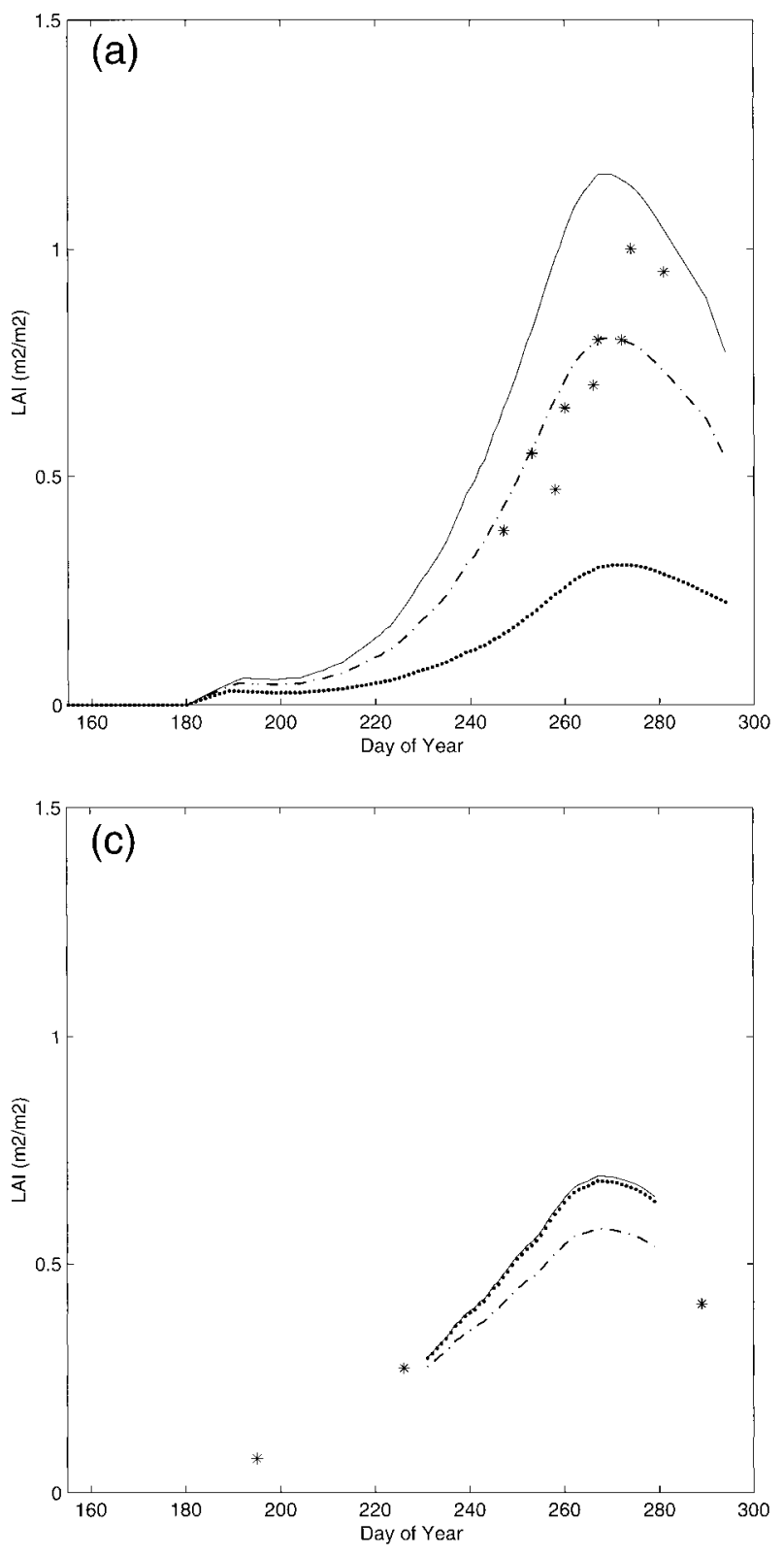

(simulations S0), the fits produce a more vigorous growth for the CES and CWS, but a similar growth or a slightly decrease for the SS. Over the CES, there seems to be a 10-day lag between the modeled and measured LAI (simulation S1). This is due to a 10-day lag between the NDVI and LAI values (Figs. 4 and 6a). This lag was also reported by van Leuwen et al. (1997) who suggested that plants and radiometric measurements were not taken exactly within the same area. As shown in Fig. 7, the SS received more precipitation than the CES and CWS, and the rain season started considerably earlier. Consequently, vegetation growth took place earlier. However, this site suffered from significant dry

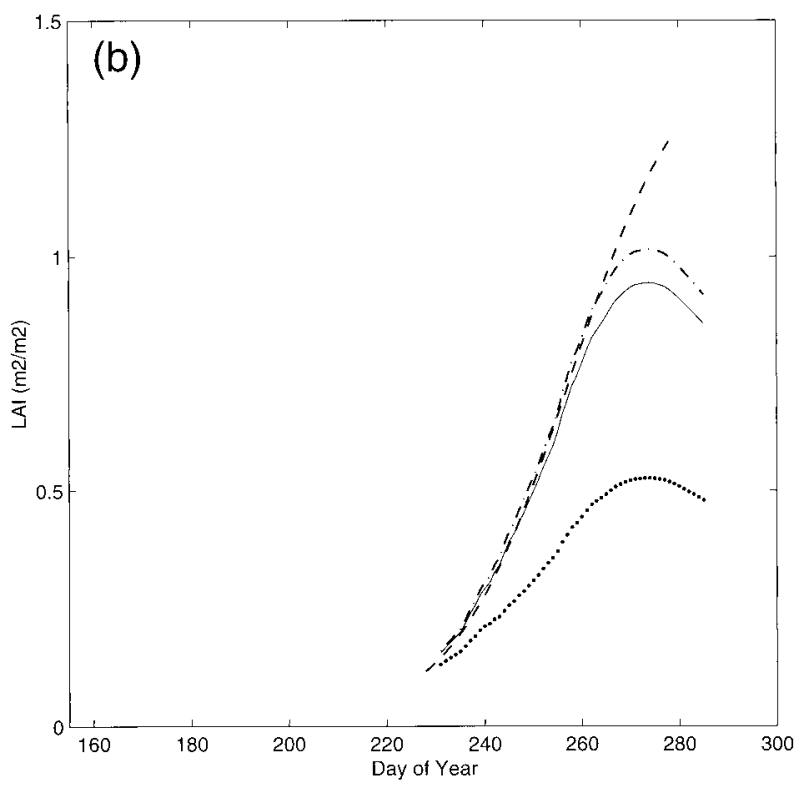

FIG. 6. (a) Comparison of LAI time-profiles measured over grassland (asterisk) with simulations of the V-S model on CES. The dotted line is the reference V-S simulation (simulation S0), the solid line is the simulation after $\mathrm{V}-\mathrm{S}$ calibration with airborne shortwave data (simulation S1), the dash-dot line is the simulation after V-S calibration with satellite shortwave data (simulation S2). (b) Comparison of LAI time profiles measured over grassland (dashed line) with simulations of the V-S model on CWS. The dotted line is the reference $\mathrm{V}-\mathrm{S}$ simulation (simulation S0), the solid line is the simulation after V-S calibration with airborne shortwave data (simulation S1), the dash-dot line is the simulation after V-S calibration with satellite shortwave data (simulation S2). (c) As Fig. 6a but for SS and over grass-shrub subsite (solid line).

spells. According to Moncrieff et al. (1997), dry spells severely impaired the grass cover, which did not fully recover despite significant rainfall from DoY 200 to 260. Interestingly, the low vigor parameter retrieved for the SS from both airborne and satellite NDVI correspond to a damaged or less efficient vegetation although the scarcity of LAI measurements precludes definitive conclusions.

The overall good agreement between the simulated and measured LAI leads to the conclusion that the V-S model can be calibrated with remotely sensed NDVI measurements. After calibration, the model captures the intersite variability of LAI much better. The SS shows 

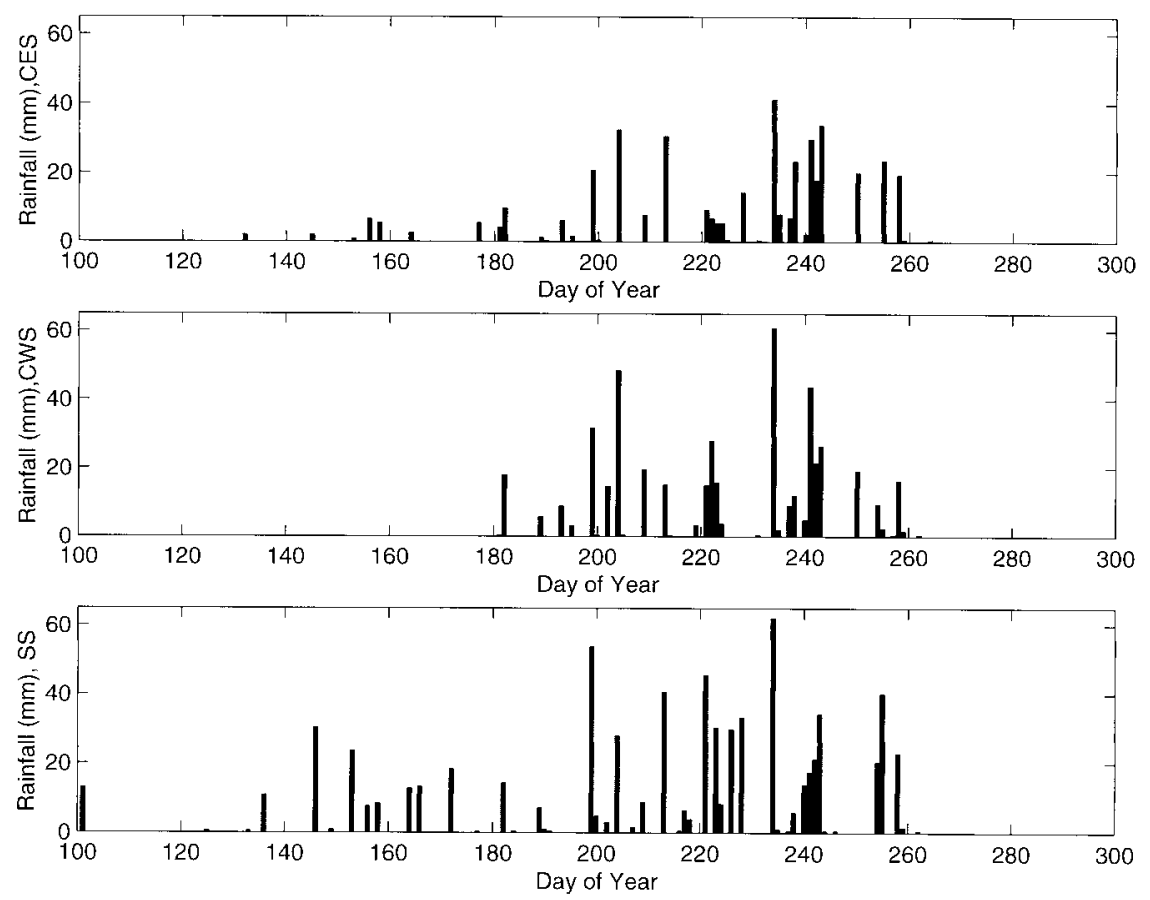

FIG. 7. Precipitation (mm) measured at the CES, CWS, and SS sites during HAPEX-Sahel 1992.

an earlier growth, but a lower maximum LAI. The CES and CWS data show a higher maximum LAI, with CWS being slightly higher than CES. These features are captured by the calibrated model and reflect a difference in the rainfall distribution, according to Levy et al. (1997). Interestingly, the results obtained with satellite NDVI seem to be even more consistent than the airborne-based results.

These calibration procedures (i.e., with either airborne or satellite NDVI data) also have a large impact on the latent heat flux, (LE), simulations. Figure 8a shows the simulated (simulations S0, S1, and S2) and measured latent heat flux over a 10-day period at peak biomass for the CES. As expected from the sensitivity study, the a priori S0 simulation of LE flux is constantly lower than the observations, because the vegetation growth is underpredicted. After calibrations, the simulated (simulations S1 and S2) and observed fluxes are in good agreement. The root-mean-square error is 60 $\mathrm{W} \mathrm{m} \mathrm{m}^{-2}$ (Table 3, simulation S2). This is satisfactory, considering the error associated with the measurements over such complex terrain (Lloyd et al. 1997). The diurnal cycle and the day-to-day variability are reasonably reproduced (Fig. 8a). Since this 10-day period takes place after the main rainfalls, there is a trend in the observed daily maximum LE. It decreases from $350 \mathrm{~W}$ $\mathrm{m}^{-2}$ on DoY 262 to $270 \mathrm{~W} \mathrm{~m}^{-2}$ on DoY 271. This trend is due to a decrease in soil moisture and is also captured by the model. Figure $8 \mathrm{~b}$ shows the seasonal course of the latent heat flux observed and simulated at 1400 UTC, averaged over five-day periods. Again, the calibrations from the NDVI time series improve the simulations (Fig. 8b). The drying period (DoY 265-290) presents larger scattering, but the overall agreement is satisfactory.

\section{b. Results of the model calibration with thermal infrared data}

Given the significant sensitivity of radiative temperature and latent heat flux to the LAI development, it is pointless to calibrate the SVAT model with radiative temperature data if the LAI is poorly reproduced. Calibration of the "thermal" parameters (coefficients for the soil resistance, section $4 \mathrm{c}$ ), when using the a priori estimates of the vegetation vigor parameters, leads to unrealistic soil parameter values and poor rmse of latent heat fluxes (Table 3, simulation S3). For example, over the CE site, the a priori S0 simulation shows an underestimated LAI and the radiative temperature is too high. To match the observed radiative temperature, the system tends to cool and drastically decreases the soil resistance. The soil dries rapidly and the vegetation growth is even further reduced. Therefore, in the following, the temperature data are used to refine the vegetation-SVAT calibration after the "shortwave data" calibration described in the previous section has been applied.

\section{1) GRound-BASED THERMAL INFRARED}

Ground measurements of radiative temperature over the grassland showed high spatial variability in addition 

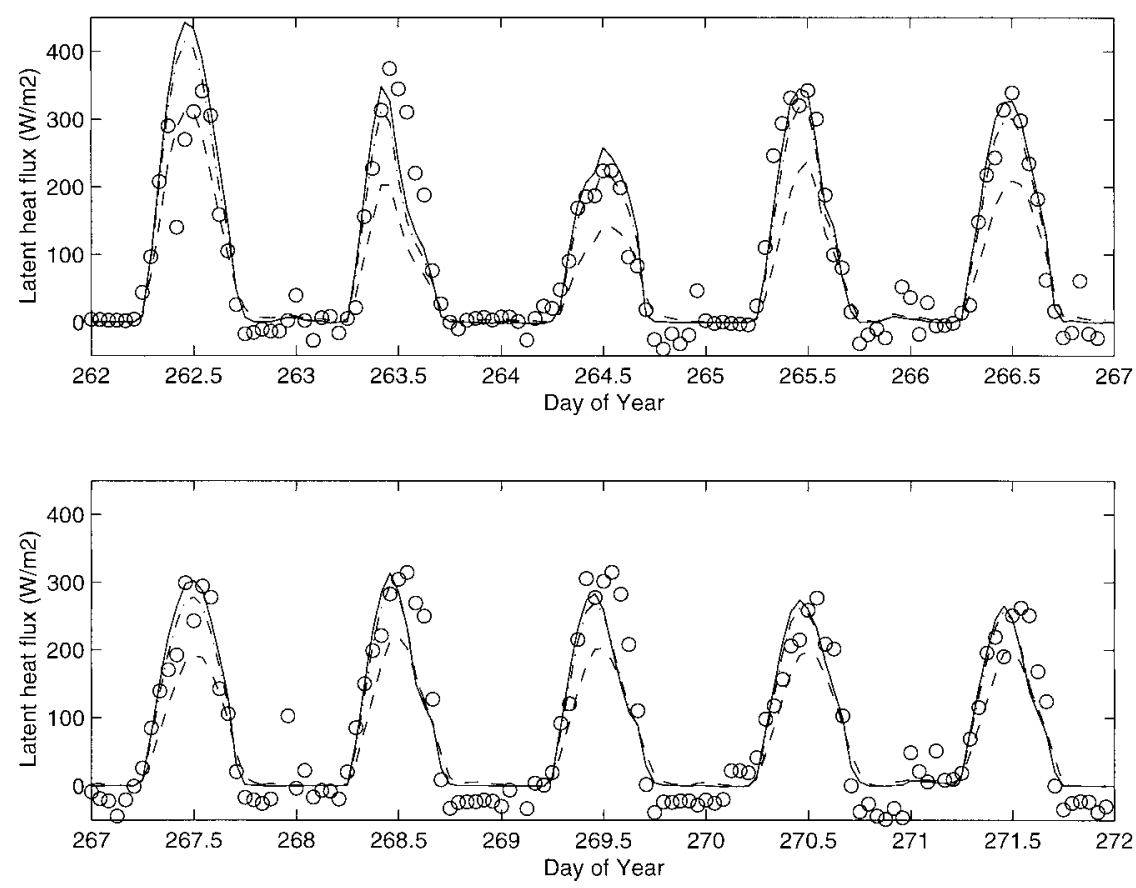

FIG. 8a. Time series of simulated and measured hourly latent heat flux on the CES during a 10day period of the growing season (Day of Year 262-271). The dashed line represents the reference $\mathrm{V}-\mathrm{S}$ simulation (simulation S0), the solid line is the simulation after $\mathrm{V}-\mathrm{S}$ calibration with airborne NDVI data (simulation S1), and the dash-dot line is the simulation after V-S calibration with satellite NDVI data (simulation S2). The circles are the measurements.

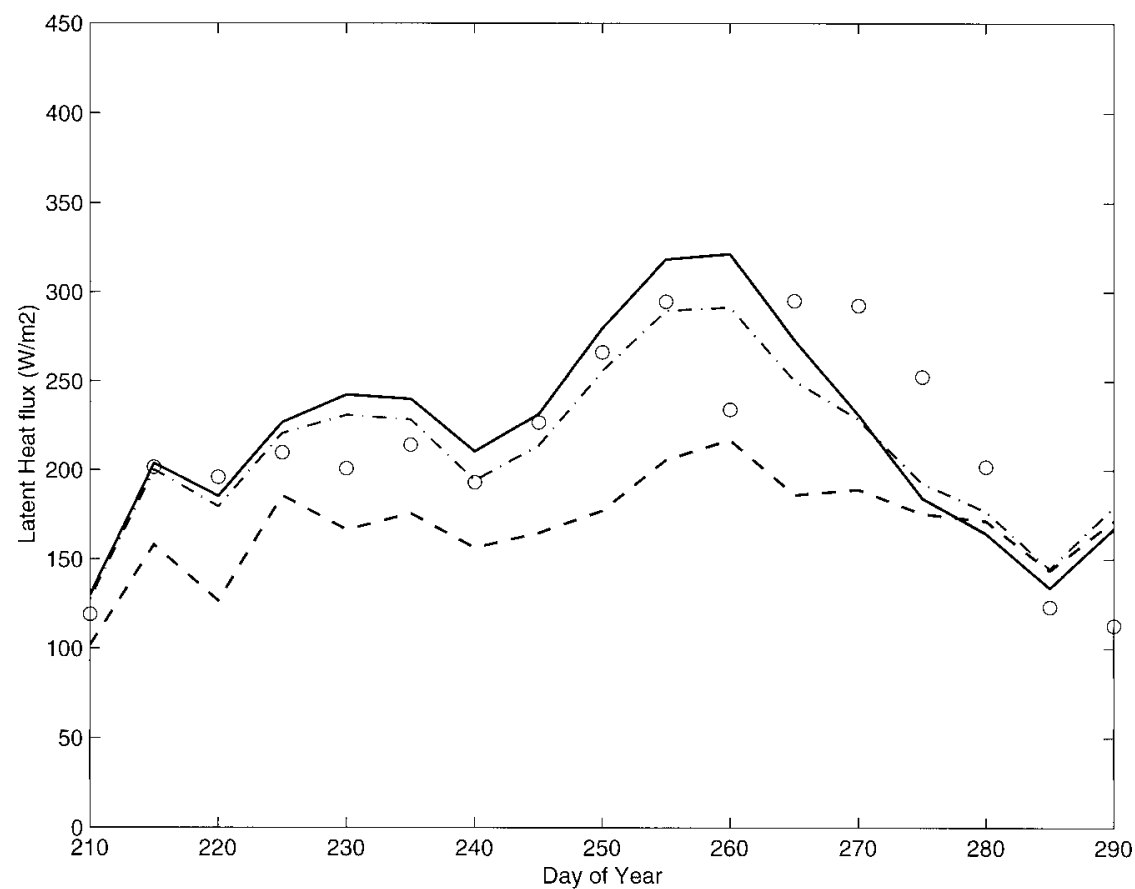

FIG. 8b. As in Fig. 8a, but for the latent heat flux at 1400 LT averaged over every five-day period of the 1992 season. 

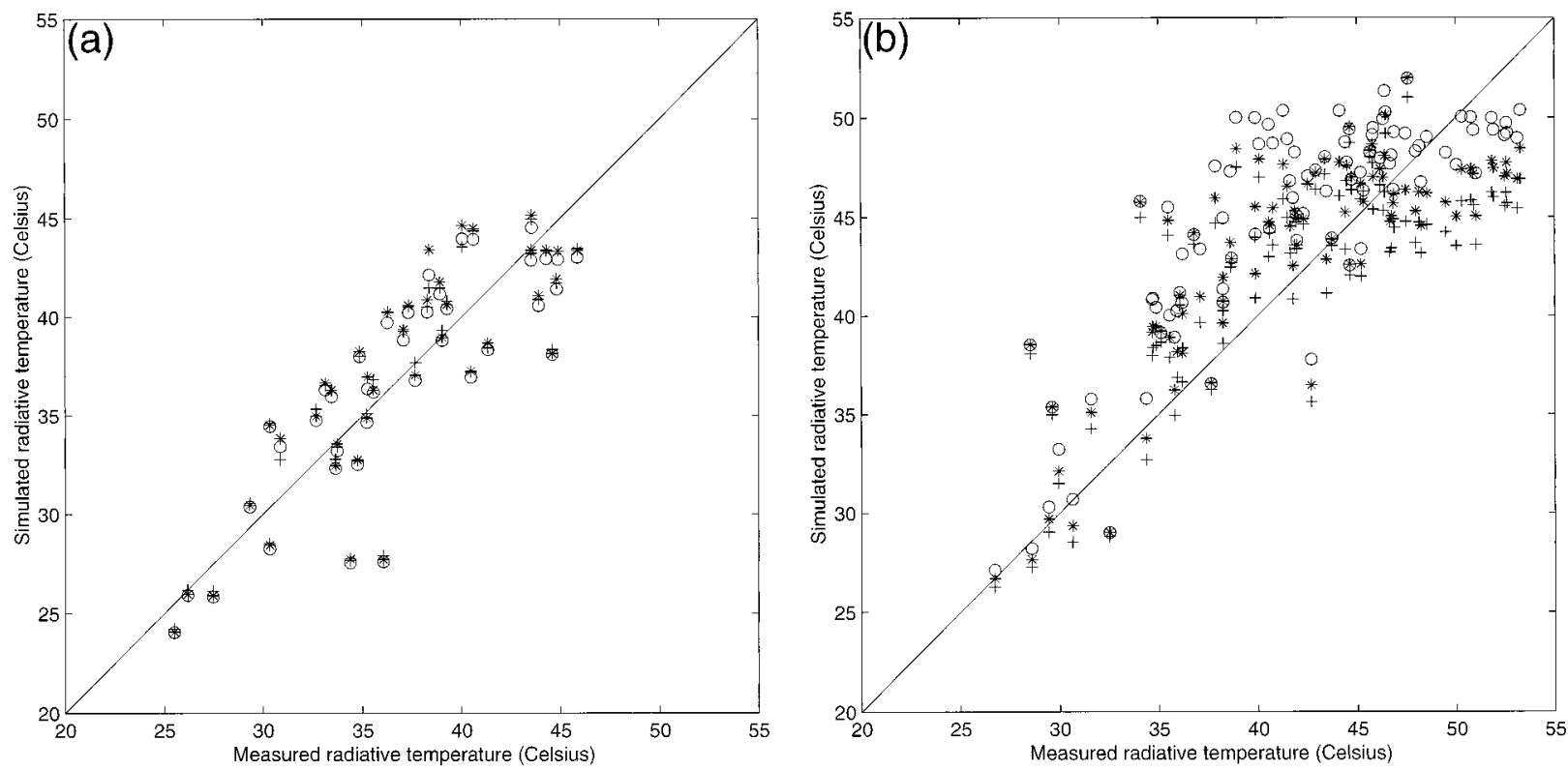

FIG. 9. (a) Comparison between V-S simulated and measured radiative temperature over the SS grassland: the circles are simulation S0, the asterisk are simulation S1, and the crosses are simulation S4. The measured radiative temperatures are the average of four measurements simultaneously performed at different locations. (b) As Fig. 9a but for CES.

to large temporal variability. The average standard deviation of four temperature sensors operating over the $\mathrm{SS}$ was $4.25 \mathrm{~K}$. Differences as large as $5 \mathrm{~K}$ were commonly found between two sensors measuring similarly vegetated areas. The grassland SS where several synchronous temperature series were acquired, was therefore the best site to investigate the calibration of the vegetation-SVAT model with temperature data. However, the LAI and fluxes measurements over the SS grassland were scarce or lacking. The impact of the TIR calibration on LAI and latent flux was therefore assessed for the $\mathrm{CE}$ site, bearing in mind that a single temperature record may not be representative of the whole site.

Over the SS, the simulation of the brightness tem-

TABLE 5. Measured ground $\left(T_{\text {ground }}\right)$ and modeled $\left(T_{\text {model }}\right)$ brightness temperature and coincident AVHRR surface temperature $\left(T_{\text {sat }}\right)$. The satellite data were retained only if the zenith view angle $\left(\theta_{v}\right)$ is less than $25^{\circ}$ and the pixel is cloud free.

\begin{tabular}{lccccc}
\hline \hline Site & Date & $\theta_{v}$ & $\begin{array}{c}T_{\text {sat }}\left({ }^{\circ} \mathrm{C}\right) \\
\text { (surface) }\end{array}$ & $\begin{array}{c}T_{\text {ground }}\left({ }^{\circ} \mathrm{C}\right) \\
(\text { brightness) }\end{array}$ & $\begin{array}{c}T_{\text {model }}\left({ }^{\circ} \mathrm{C}\right) \\
\text { (brightness) }\end{array}$ \\
\hline CES & 174 & 9.8 & 46.85 & $+{ }^{*}$ & 48.38 \\
CES & 190 & 5.27 & 43.65 & + & 48.36 \\
CES & 198 & 11.79 & 43.05 & + & 49.5 \\
CES & 232 & 4.39 & 35.65 & 40.3 & 38.47 \\
CES & 249 & 14.17 & 32.45 & 38.71 & 38.79 \\
CES & 290 & 7.43 & 37.25 & 47.3 & 38.17 \\
CWS & 232 & 8.33 & 37.25 & + & 39.74 \\
CWS & 249 & 18.46 & 38.85 & + & 40.81 \\
SS & 232 & 20.17 & 32.45 & + & 35.82 \\
SS & 249 & 21.02 & 37.25 & 37 & 37.8 \\
SS & 272 & 23.27 & 38.8 & 37.4 & 36.5 \\
\hline
\end{tabular}

*The symbol "+" means no data available. perature was reasonably good for the reference simulation. The rmse was $3.1 \mathrm{~K}$ and the Nash-Sutcliffe efficiency $R^{2}$ was 0.67 (Table 3, simulation S0). Since the calibration of the vegetation vigor parameters with airborne and satellite NDVI only slightly changed the simulation (Fig. 6c and Table 4), the impact on the simulated temperature was also weak (Fig. 9a, Table 3, simulations $\mathrm{S} 1$ and S2). This first step calibration resulted in an rmse of $3.1 \mathrm{~K}$ and a Nash-Sutcliffe efficiency of 0.68 (Table 3, simulation $\mathrm{S} 1$ ). When the soil resistance parameters were adjusted to match the measured temperature (simulation S4), the rmse was slightly improved $(3 \mathrm{~K})$, as was the Nash-Sutcliffe efficiency (0.69). This was mainly due to a slight improvement of the temperature of about $0.5^{\circ}$ at the end of the season. Over the 44-day period, the average latent heat flux at 1400 UTC was $190 \mathrm{~W} \mathrm{~m}^{-2}$ for the a priori S0 simulation and $179 \mathrm{~W} \mathrm{~m}^{-2}$ after calibration (simulation S4). Due to the lack of latent heat flux data over the SS grassland, the impact of this TIR calibration could not be further assessed for this site.

For the CES, the reference simulation S0 was poor in terms of LAI and LE (rmse $=75 \mathrm{~W} \mathrm{~m}^{-2}$, Table 3). As previously shown, the calibration of plant vigor with shortwave data improved both LAI and LE ( $\mathrm{rmse}=63$ $\mathrm{W} \mathrm{m} \mathrm{m}^{-2}$ and $60 \mathrm{~W} \mathrm{~m}^{-2}$, Table 3 , simulations $\mathrm{S} 1$ and $\mathrm{S} 2$ ). It also improved the simulation of the brightness temperature. The rmse was $4.92 \mathrm{~K}$ before (simulation $\mathrm{S} 0$ ) and $4.2 \mathrm{~K}$ after the shortwave calibration (simulation $\mathrm{S} 1)$. The calibration of the soil resistance with thermal infrared data, which was performed after the shortwave calibration, increased the brightness temperature (Fig. 
9b) and brought the temperature rmse to $4.1 \mathrm{~K}$ (simulation S4). However, this longwave calibration did not add much to the simulation of the latent heat flux when compared with the shortwave calibration ( $\mathrm{rmse}=62$ $\mathrm{W} \mathrm{m} \mathrm{m}^{-2}$ instead of $63 \mathrm{~W} \mathrm{~m}^{-2}$, Table 3, simulations S4 and $\mathrm{S} 1$, respectively). These results do not change when simulation S4 is iterative. The vigor parameter and soil resistance coefficients stabilize at 1.34 and 8300/1900. Similar results are obtained when all these parameters are calibrated simultaneously using the following cost function

$$
\sqrt{\frac{\sum_{i=1}^{D}\left(\mathrm{NDVI}_{\mathrm{sim}}^{i}-\mathrm{NDVI}_{\mathrm{obs}}^{i}\right)^{2}}{\sum_{i=1}^{D}\left(\mathrm{NDVI}_{\mathrm{obs}}^{i}-\overline{\mathrm{NDVI}_{\mathrm{obs}}^{i}}\right)^{2}}+\frac{\sum_{j=1}^{T}\left(T_{\mathrm{sim}}^{j}-T_{\mathrm{obs}}^{j}\right)^{2}}{\sum_{j=1}^{T}\left(T_{\mathrm{obs}}^{j}-\overline{T_{\mathrm{obs}}^{j}}\right)^{2}}}
$$

( $T^{j}$ is the radiative temperature, $D$ and $T$ are the number of observations, the indices "sim" and "obs" refer to simulated and observed, respectively). Thus, our conclusions seem to be robust.

\section{2) SAtellite THERMAl INFRARED DATA}

Table 5 presents the AVHRR surface temperature obtained with a split window technique (Kerr et al. 1992), along with the ground measurements of brightness temperature (emissivity is 1 ) for the same sites and the same hours. It also shows the brightness temperature estimated by the V-S model, [Eq. (1)], that was calibrated with AVHRR shortwavelength data (S2 simulations) on the three sites. The model therefore has realistic vegetation dynamics. Because of cloud contamination and view angle restriction, the number of afternoon AVHRR scenes with coexistent ground data is low. Table 5 shows that the AVHRR temperature is significantly lower than the simulated brightness temperature. On the CES, differences of $5^{\circ}$ are common during the growing season. The difference is larger when the emissivity is considered. As shown by van de Griend et al. (1991), thermal infrared emissivities $(8-14 \mu \mathrm{m})$ of natural surfaces within the savanna environment may vary between 0.914 for bare soil and 0.986 for a vegetated surface. The corresponding surface temperatures are 6 and $1 \mathrm{~K}$ higher than the brightness temperature, respectively, for a brightness temperature around $300 \mathrm{~K}$.

Not surprising, this difference between AVHRR temperature and simulated brightness temperature has a large impact on the calibration scheme, even if a very high emissivity is assumed. An adjustment of the soil resistance parameters was performed to match the AVHRR surface temperature after the plant vigor had been calibrated with AVHRR NDVI time series. No emissivity correction was applied to the AVHRR surface temperature, so the difference between modeled and measured temperature is underestimated. Because the model attempts to drastically cool the surface, the calibration leads to unrealistic parameters values. As a re- sult, the calibration of the vegetation-SVAT model with AVHRR surface temperature data was unsuccessful at this stage. Some reasons for these discrepancies are discussed in the following section.

\section{Discussion}

This study describes the first attempt to calibrate a $\mathrm{V}-\mathrm{S}$ model with satellite shortwave and longwave data over several uncultivated vegetation sites. This methodology produced several interesting results and is suitable to address upscaling problems for surface fluxes and vegetation growth modeling. On the other hand, it also pointed out some difficulties in using satellite longwave data. Among the more interesting results was the ability to constrain the $\mathrm{V}-\mathrm{S}$ model using shortwave satellite data. Similar conclusions were obtained with cropgrowth models (Moulin et al. 1998). However, crop models benefit from numerous control studies that simply do not exist for natural vegetation. It was therefore important to establish the suitability of the calibration methodology in the case of natural vegetation. These results also showed that modeling of the canopy shortwave radiative properties (NDVI) with the SAIL model is robust and can be applied to multispecies sparse canopies. The results obtained with airborne and satellite shortwave data were similar. This shows that the data processing, the heterogeneity treatment (linear unmixing), and the links between LAI and NDVI are accurate enough to make full use of operational sensors and data streams. One should note that the initial conditions for growth had to be prescribed in this study, especially for the CWS and SS. Therefore, the ability to constrain the phenology (i.e., growth timing) could not be completely assessed. Yet, phenology may also be a good candidate for calibration (Kergoat et al. 1995a; Moulin et al. 1997). Reducing the number of parameters, as we did for the vegetation "vigor," should allow us to constrain both vigor and phenology with NDVI time series. The second interesting result was that the simulation of the surface fluxes was fairly good (rmse for heat latent flux on the grassland CES is $60 \mathrm{~W} \mathrm{~m}^{-2}$ ), once the $\mathrm{V}-\mathrm{S}$ model had been calibrated from satellite shortwave data. In particular, the simulation of the site-to-site variability was greatly enhanced by the calibration procedures. Assimilating shortwave satellite data into a $\mathrm{V}-\mathrm{S}$ model appears to be particularly suited to assess the water and energy exchanges at the regional scale, as well as their seasonal variations.

The use of radiative temperature was less successful. We showed that some parameters that are directly related to the energy balance could be calibrated with groundbased brightness temperature measurements. However, this further calibration did not add much to the simulation of surface fluxes. Two different reasons could explain this result: (a) the NDVI data may possess a "better" information content, or (b) this may simply reflect the greater sensitivity of the fluxes to the LAI 


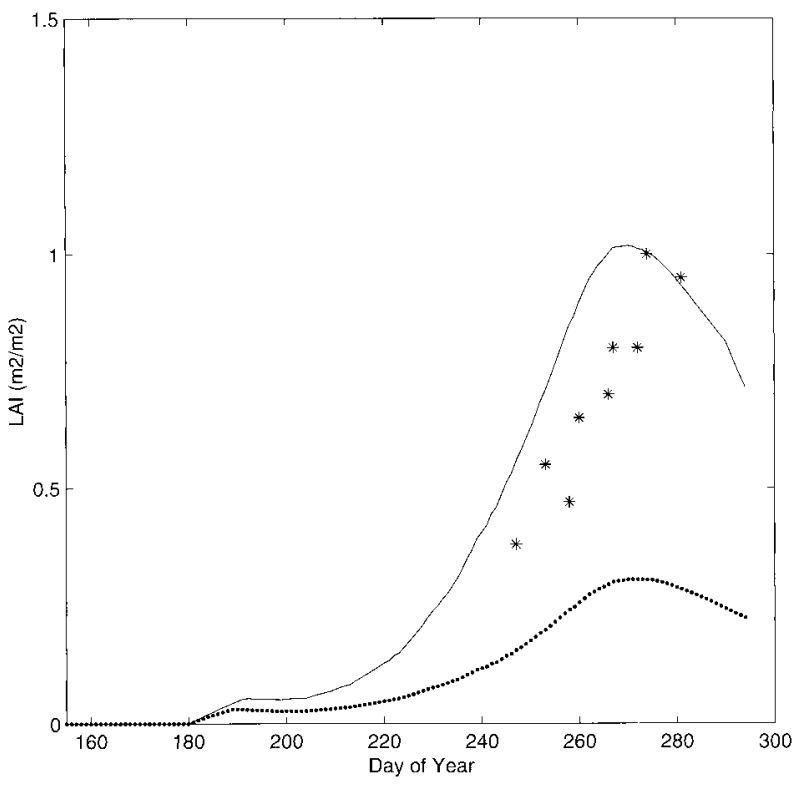

FIG. 10. Comparison of the LAI time profile measured over the CES grassland (asterisks) with the V-S simulations. The dotted line is the reference simulation (simulation S0), and the solid line is the LAI simulation after $\mathrm{V}-\mathrm{S}$ calibration with ground-based radiative temperature data (simulation S5).

calibration than to the resistance parameters. To assess further these questions, we performed a calibration of the vegetation vigor parameters $V$ using the ground TIR data instead of the NDVI (simulation S5, $V=1.2$ with a confidence interval at $95 \%$ of $[0.96,1.43])$. As shown by Fig. 10, this calibration improved the LAI simulation, as compared with the a priori S0 case for the CES. It also improved the simulation of the latent heat flux and radiative temperature (Table 3 , simulation S5). Indeed, using either ground-based TIR or NDVI data lead to very similar results. The conclusion of this test is that the TIR data also contains "useful" information. Although both NDVI and TIR data were suitable to constrain the V-S model, the synergy between the two wavelengths was not clearly demonstrated. The main reason for that is the high sensitivity of the V-S model's temperature and fluxes to vegetation cover. This conclusion is probably valid for semiarid areas only, where vegetation development and soil moisture are highly correlated on a seasonal basis [see Ottlé and Vidal-Madjar (1993) for a different case].

The last insight was that satellite longwave data proved unsuitable for model calibration at this stage. The AVHRR surface temperature values were found to be much lower than the ground-based measurements over the grassland sites, and this brings into question the temperature retrieval algorithm. Based on very limited datasets over some HAPEX-Sahel subsites, the split window algorithm used in this study was favorably compared to other algorithms by Andersen et al. (1997), whereas Caselles et al. (1997) suggested that it could underestimate surface temperature by $3.5^{\circ}$. Indeed, comparison between satellite data and ground data is often a challenge in itself. This is particularly true for the AVHRR over land. As noted by Kerr et al. (1998) and Zhihao Qin and Karnieli (1999), the main problems for comparison can be summarized as follows:

- It is difficult to assess the emissivity values to correct the ground measurements.

- The AVHRR sensor and the radiometers used for ground measurements have different spectral responses.

- The pixels are not pure and the ground data representativeness may be questioned. Unlike in the red and near-infrared bands, the linear unmixing method cannot be applied to the AVHRR surface temperature measurements because the assumption that each vegetation type shows the same surface temperature over contiguous pixels does not hold.

- The difference in the acquisition time at the ground and satellite level can be a major source of error second to the heterogeneity problem.

For all these reasons, it is extremely difficult to compare ground measurements and satellite data. As a result, the interpretation of remotely sensed longwave data has not reached the same maturity that the interpretation of shortwave data has. The results from the FIFE experiment lead to similar conclusions (Schmugge and Schmidt 1998). In that case, the spatial heterogeneity was also the best candidate to explain the discrepancies.

The use of differential measurements of surface temperature may circumvent some of the measurement problems. For example, the diurnal cycle provided by GOES-8 and future Meteosat second-generation may help to constrain SVAT (Jones et al. 1998a) or V-S models, even in the presence of systematic biases between modeled- and satellite-derived temperatures. In this study, the results based on ground data established that there is potential to use the temperature measurement in conjunction with $\mathrm{V}-\mathrm{S}$ models. In comparison with the shortwave data, there is more room for improving the satellite-based algorithms.

\section{Conclusions}

This study presented a coupled vegetation-SVAT model ( $\mathrm{V}-\mathrm{S}$ model) and investigated the feasibility in calibrating the $\mathrm{V}-\mathrm{S}$ model with ground-based, airborne, and satellite data in the shortwave and longwave domains. The coupled vegetation-SVAT model was described and calibrated using ground data collected over three semiarid grassland sites during the HAPEX-Sahel experiment. A sensitivity analysis showed that the parameters related to plant growth vigor and to soil evaporative resistance were the best candidates for calibration. The radiative temperature is equally sensitive to the vegetation parameters and to the water and energy parameters (i.e., the vegetation cover has considerable 
effect on radiative temperature). This emphasizes the importance of the accuracy of LAI simulation. The impact of calibrating model parameters with time series of AVHRR normalized vegetation index and thermal infrared data was assessed by examining the simulations of latent heat flux and LAI for a suite of calibration experiments. The results showed that both airborne and AVHRR NDVI data can be used to constrain the V-S model. These constraints significantly improved the simulations of the LAI and latent heat flux. In particular, the site-to-site variability was greatly enhanced by the calibration procedures. The model can also be calibrated with ground-based radiative temperature data. Although both NDVI and temperature data were suitable to constrain the $\mathrm{V}-\mathrm{S}$ model, the synergy between the two wavelengths was not clearly demonstrated. Moreover, satellite surface temperature data proved unsuitable for model calibration at this stage. The AVHRR surface temperature values were found to be much lower than the ground-based measurements over the grassland sites. Therefore, the best simulations of LAI and latent heat flux were obtained by constraining the $\mathrm{V}-\mathrm{S}$ model with NDVI satellite data; the main reason was that the relationships between the satellite signal and the surface variables seem to be more robust in the short-wave domain than in the thermal infrared domain. The use of satellite thermal infrared still requires further work to alleviate the challenging heterogeneity and accuracy problems. As a conclusion, we think that the calibration of a coupled vegetation growth-SVAT model (V-S) with shortwave satellite data can now be used to improve the simulation of the seasonal and spatial variability of the surface energy and water exchanges. This approach may be used to address the scaling of the surface fluxes up to the regional scale.

Acknowledgments. This work was made possible through a Ph.D. grant from French MESR (Ministère de l'Enseignement Supérieur et de la Recherche), the support of the European Commission to the Vegetation Preparatory Program, and of the Fourth Environment and Climate Program. The authors wish to express their sincere gratitude to the HAPEX-Sahel Information System at CESBIO. Yann Kerr is gratefully acknowledged for stimulating discussions. Special thanks are due to the many people involved in the implementation of the experiment, particularly to Drs. B. A. Monteny, S. D. Prince, N. P. Hanan, and P. E. Levy. The authors also thank Cristina Kaufman for carefully reading and editing the manuscript. We would like to thank gratefully the anonymous reviewers for their constructive criticism.

\section{APPENDIX A \\ Description of the Coupled Vegetation-SVAT Model}

a. Water and energy balance submodel

The SVAT model presented in this paper describes the major land surface water and energy exchange pro- cesses between the biosphere and the atmosphere. The surface is represented using the two-sources approach proposed by Shuttleworth and Wallace (1985). Soil and vegetation contributions to sensible and latent heat fluxes are explicitly parameterized. The incoming solar radiation is partitioned between bare soil and vegetation through a screen factor $\sigma_{f}$ (i.e., Deardorff 1978; Taconet et al. 1986). The shielding factor $\sigma_{f}$ is expressed as a function of the LAI following Beer's law: $\sigma_{f}=1-$ $\exp (0.4 \mathrm{LAI})$. Note that variables are defined in Appendix B. The energy balance, written separately for the soil and the vegetation, gives

$$
\begin{gathered}
\mathrm{Rn}_{s}-\mathrm{LE}_{s}-H_{s}-G=0 \text { and } \\
\mathrm{Rn}_{c}-\mathrm{LE}_{c}-H_{c}=0
\end{gathered}
$$

where $\mathrm{Rn}$ is the net radiation, LE is latent heat flux, $H$ is sensible heat flux, $G$ is ground heat flux, and the indices $s$ and $c$ refer to soil and canopy, respectively.

The network of resistances from Shuttleworth and Wallace (1985), between the soil surface, the withincanopy source level, and the above-canopy reference level allows estimation of the latent and sensible heat fluxes through differences in vapor pressure and in temperature:

$$
\begin{aligned}
\mathrm{LE} & =\frac{\rho C_{p}}{\gamma}\left(\frac{e_{o}-e_{a}}{r_{a a}}\right) \text { and } \\
H & =\frac{\rho C_{p}\left(T_{0}-T_{a}\right)}{r_{a a}} .
\end{aligned}
$$

For the soil component:

$$
\begin{aligned}
\mathrm{LE}_{s} & =\frac{\rho C_{p}}{\gamma}\left[\frac{e_{\mathrm{sat}}\left(T_{g}\right)-e_{o}}{r_{a s}+r_{\mathrm{ss}}}\right] \text { and } \\
H_{s} & =\frac{\rho C_{p}\left(T_{g}-T_{o}\right)}{r_{a s}} .
\end{aligned}
$$

For the vegetation component:

$$
\begin{aligned}
\mathrm{LE}_{c} & =\frac{\rho C_{p}}{\gamma}\left[\frac{e_{\mathrm{sat}}\left(T_{c}\right)-e_{o}}{r_{a c}+r_{c}}\right] \text { and } \\
\mathrm{H}_{c} & =\frac{\rho C_{p}\left(T_{c}-T_{o}\right)}{r_{a c}} .
\end{aligned}
$$

The resistance formulations are found in appendix $\mathrm{C}$, except for the canopy resistance $\left(r_{c}\right)$, which is detailed in appendix $\mathrm{Ab}(3)$.

The volumetric soil water content of ground surface $\left(w_{g}\right)$ and of roots layer $\left(w_{2}\right)$ result from the water balance, which is based on the force-restore approach developed by Deardorff (1978) and adapted by Noilhan and Planton (1989): 


$$
\begin{aligned}
& \frac{\partial w_{g}}{\partial t}=\frac{C_{1} G}{\rho_{w} d_{1}}\left(P-E_{g}\right)- \frac{C_{2}}{\tau}\left(w_{g}-w_{\mathrm{eq}}\right) \\
& \text { when } 0<w_{g} \leq w_{\mathrm{fc}}
\end{aligned}
$$

and

$$
\frac{\partial w_{2}}{\partial t}=\frac{\left(P-E_{g}-E_{\mathrm{tr}}\right)}{\rho_{w} d_{2}} \quad \text { when } 0<w_{2} \leq w_{\mathrm{fc}} .
$$

\section{b. Vegetation growth submodel}

The vegetation model aims at simulating the time evolution of three compartments: the shoots biomass, $\left(M_{s}\right)$, the roots biomass, $\left(M_{r}\right)$, and the standing necromass, $\left(M_{n}\right)$. The main processes that drive these three variables are photosynthesis, allocation of photosynthates to both shoots and roots, respiration, and senescence. The overall structure of this vegetation model is similar to some crop growth or grassland models (e.g., Spitters et al. 1989; Mougin et al. 1995; Lo Seen et al. 1995; Nouvellon 1999). The canopy gas exchange scheme, that is, stomatal and canopy resistance and photosynthesis, has been used for various biomes, and is described in Kergoat (1998).

\section{1) Carbon balance}

The dynamics of the three carbon compartments are described by a set of differential equations:

$$
\begin{aligned}
& \frac{d M_{s}}{d t}=a_{s} \operatorname{Pn}-m_{s} M_{s}-\mathrm{Rg}_{s}-s_{s} M_{s}, \\
& \frac{d M_{r}}{d t}=\left(1-a_{s}\right) \operatorname{Pn}-m_{r} M_{r}-\mathrm{Rg}_{r}-s_{r} M_{r}, \quad \text { and } \\
& \frac{d M_{n}}{d t}=s_{s} M_{s}-d_{n} M_{n} .
\end{aligned}
$$

Equation (A11) expresses that the daily carbon increment of the shoots is the result of the carbon gain [photosynthesis, Pn, minus the carbon losses (respiration and senescence: $\left.s_{s} M_{s}\right)$ ]. Plant respiration consists of the maintenance $\left(m_{s}, M_{s}\right)$ and growth respiration $\left(\operatorname{Rg}_{s}\right)$. The carbon fixed through photosynthesis is partitioned between the shoots and roots according to the allocation coefficient $\left(a_{s}\right)$. The roots obey a similar equation [Eq. (A12)], with a symmetric allocation coefficient (1 $\left.a_{s}\right)$. The necromass dynamics depend on the difference between necromass production, which is equal to the shoots senescence, $s_{s} M_{s}$, and necromass decay, $d_{n} M_{n}$.

The LAI is computed from the shoots biomass according to a nonlinear relationship that accounts for the increasing importance of stems and other nonleaf tissues at high levels of biomass [empirical relationship, e.g., Le Roux (1995)] by the expression

$$
\mathrm{LAI}=\operatorname{SLA}_{0}\left[1-0.48\left(1-e^{-25.5 M_{s}}\right)\right] M_{s},
$$

where $\mathrm{SLA}_{0}$ is the specific leaf area for low levels of the shoots biomass.

The carbon balance equations [Eqs. (A11)-(A13)] are solved on a daily basis, whereas the photosynthesis (Pn) is computed and accumulated on an hourly basis. Indeed, it depends on the stomatal resistance, which is also involved in the SVAT model, and computed on an hourly basis.

\section{2) CARbon pools initialization}

For the annual vegetation considered in this study, the shoots and roots compartments are initially empty at the beginning of the rain season. Model initialization consists of using a prescribed amount of carbon, which represents the seeds that germinate, to grow the first leaves and roots. This process is parameterized using an initial amount of carbon and a daily rate at which this carbon is injected into the two compartments (IC and Trans parameters in appendix B). For two sites (CWS and SS), the meteorological data during the first part of the growing season were not available. Therefore, the shoots biomass was initialized to correspond to the biomass field measurements for the first day of the simulations (Day 231 of 1992 for CWS and SS). Moreover, as the simulations do not really extend into the dry season, the necromass decay was neglected ( $\mathrm{dn}$ set to 0, appendix B). For the CES site, the start of the growing season (germination) was set to day of year (DoY) 180.

\section{3) Photosynthesis and Resistance scheme}

The vegetation model uses a scheme that accounts for the response of canopy photosynthesis to soil and atmosphere forcing. At an hourly time step, a leaf level photosynthesis model is integrated to the canopy level according to canopy LAI. The rate of leaf photosynthesis, $P_{l}$, is given by

$$
P_{l}=\frac{\mathrm{Ca}-\Gamma}{r_{s}+r_{r}},
$$

where $\mathrm{Ca}-\Gamma$ is the difference in $\mathrm{CO}_{2}$ concentration between the chloroplast and the atmosphere; $r_{s}$ and $r_{r}$ are the stomatal and residual resistances to $\mathrm{CO}_{2}$ transfer (e.g., Running and Coughlan 1988). The stomatal resistance is a Jarvis type resistance (Jarvis 1976), where a minimum resistance, $r_{s \min }$, is increased according to stress factors,

$$
\begin{aligned}
r_{s} & =r_{s \min } f(I) g\left(w_{2}\right) h(\mathrm{VPD}) \\
& =r_{s \min } \frac{I_{s}+I}{I} \frac{w_{\mathrm{fc}}-w_{\mathrm{wp}}}{w_{2}-w_{\mathrm{wp}}} \frac{4000-1000}{4000-\mathrm{VPD}},
\end{aligned}
$$

where $I$ and $I_{s}$ represent the incoming Photosynthetically Active Radiation (PAR) and the PAR level for stomata half-closure (Saugier and Katerji 1991), respectively; here, $w_{2}$ is the soil moisture content of the root zone; 
and $w_{\mathrm{wp}}$ and $w_{\mathrm{fc}}$ are the soil moisture at wilting point and at field capacity, respectively. The term VPD is the water vapor deficit $(\mathrm{Pa})$.

Photosynthesis biochemistry is represented by the $g_{1}$ and $g_{2}$ factors in the residual resistance equation and accounts for PAR and temperature effects (Running and Coughlan 1988),

$$
\begin{aligned}
r_{r} & =r_{r \min } g_{1}(I) g_{2}(T) \\
& =r_{r \min } \frac{I_{r}+I}{I} \frac{\left(T_{\max }-T_{\min }\right)^{2}}{4\left(T_{\max }-T\right)\left(T-T_{\min }\right)},
\end{aligned}
$$

where $T$ is the air temperature.

For both resistances [Eqs. (A16) and (A17)], the light factors are simple analytical functions, which ensure a classical hyperbolic light response of leaf photosynthesis, $P_{1}$, versus PAR, in the absence of stresses. The parameters for the residual resistance, $r_{r \min }$ and $I_{r}$, are calibrated according to Eqs. (A18) and (A19) to match literature values for the maximum rate of photosynthesis, $P_{\max }$ [Eq. (A18)], and the quantum yield, $\alpha$ [Eq. (A19)]:

$$
\begin{aligned}
P_{\max } & =\frac{\mathrm{Ca}-\Gamma}{r_{s \min }+r_{r \min }} \text { and } \\
\alpha & =\frac{\mathrm{Ca}-\Gamma}{\left(r_{s \min } I_{s}+r_{r \min } I_{r}\right)} .
\end{aligned}
$$

The minimum stomatal resistance, $r_{s \min }$, comes from ground measurements of Hanan et al. (1997). This photosynthesis scheme reproduces the main features of plant photosynthesis response, that is, the effects of PAR, soil water, air temperature, water vapor deficit, and seasonal variations. Combined with a classical Beer's law for light extinction in the canopy, this leaf level model leads to an analytical expression when integrated to the canopy level:

$$
\begin{aligned}
P_{c}= & \tau_{p} \int_{0}^{\mathrm{LAI}} P_{1} d L \\
\text { i.e., } & \\
P_{c}= & \frac{\tau_{p}(\mathrm{Ca}-\Gamma)}{k_{e}\left(r_{s}^{\prime}+r_{r}^{\prime}\right)} \\
& \times \ln \frac{r_{s}^{\prime} I_{s}+r_{r}^{\prime} I_{r}+k_{e} I_{0}\left(r_{s}^{\prime}+r_{r}^{\prime}\right)}{r_{s}^{\prime} I_{s}+r_{r}^{\prime} I_{r}+k_{e} I_{0}\left(r_{s}^{\prime}+r_{r}^{\prime}\right) \exp \left(-k_{e} \mathrm{LAI}\right)},
\end{aligned}
$$

where $P_{c}$ is the hourly canopy photosynthesis, $I_{0}$ is the incoming PAR at the top of the canopy, $\tau_{p}$ is the SVAT time step, $k_{e}$ is the extinction coefficient for PAR in the canopy; $r_{s}^{\prime}$ is for $r_{s \min } g(W) h(\mathrm{VPD})$, and $r_{r}^{\prime}$ is for $r_{r \min } g_{2}(T)$. The hourly canopy photosynthesis, $P_{c}$, is accumulated to produce the daily photosynthesis (Pn) used in Eqs. (A11) and (A12).

The canopy resistance for water vapor diffusion, $r_{c}$, which is used by the SVAT submodel, is also given by an analytical formula:

$$
\begin{aligned}
\frac{1}{r_{c}} & =\int_{0}^{\mathrm{LAI}} \frac{1.6}{r_{s}} d L \\
\text { i.e., } \quad \frac{1}{r_{c}} & =\frac{1.6}{k_{e} r_{s}^{\prime}} \ln \frac{I_{s}+k_{e} I_{0}}{I_{s}+k_{e} I_{0} \exp \left(-k_{e} \mathrm{LAI}\right)},
\end{aligned}
$$

where 1.6 is the ratio of the $\mathrm{CO}_{2}$ and water vapor diffusivities.

\section{4) RESPIRATION AND SENESCENCE}

Following McCree (1970) and Amthor (1986, 1989), the total respiration consists of maintenance and growth respirations. The maintenance respiration is proportional to the biomass and its rate $\left[m_{s}\right.$ or $m_{r}$ in Eqs. (A11) and (A12)] depends on air temperature according to a classical $Q 10$ relationship:

$$
m_{s}=m_{s 0} Q_{10}^{T / 10}
$$

where $T$ is the daily average air temperature and $m_{s 0}$ $\left(m_{r 0}\right)$ is the respiration rate at $0^{\circ} \mathrm{C}$ for the shoots (roots). The growth respiration is proportional to the amount of new tissues and therefore Eqs. (A11) and (A12) are rearranged as follows:

$$
\begin{aligned}
\frac{d M_{s}}{d t} & =\frac{1}{1+g_{s}}\left(a_{s} \mathrm{PN}-m_{s} M_{s}\right)-s_{s} M_{s} \text { and } \\
\frac{d M_{r}}{d t} & =\frac{1}{1+g_{r}}\left[\left(1-a_{s}\right) \mathrm{PN}-m_{r} M_{r}\right]-s_{r} M_{r},
\end{aligned}
$$

where $g_{s}\left(g_{r}\right)$ is the amount of carbon released by growth respiration per unit of new shoots (roots) tissue. Typical values for the respiration parameters were taken from Amthor (1989). Last, the dry matter is lost through the senescence of shoots and roots tissues [Eqs. (A23) and (A24)]. We considered here a senescence rate, $s_{s 0},\left(s_{r 0}\right.$ for roots) and a water stress effect that increases senescence:

$$
\begin{aligned}
s_{s} M_{s} & =s_{s 0} f\left(w_{2}\right) M_{s} \\
& =s_{s 0}\left[1+\left(1-\frac{w_{2}-w_{\mathrm{wp}}}{w_{\mathrm{fc}}-w_{\mathrm{wp}}}\right)\right] M_{s} .
\end{aligned}
$$

\section{APPENDIX B} Variables, Parameters, and Constants Used in the
Vegetation-SVAT Model

\begin{tabular}{lcc}
\hline \hline Symbol & Definition & Type \\
\hline $\mathrm{Ca}-\Gamma$ & $\mathrm{CO}_{2}$ concentration gradient be- & Parameter \\
& tween leaf surface and chloro- & \\
& plast $\left(\mathrm{Ca}-\Gamma=0.640 \mathrm{~g} \mathrm{CO}_{2}\right.$ & \\
& $\left.\mathrm{m}^{-3}\right)$ & \\
$C_{p}$ & Specific heat at constant pressure & Constant \\
& $\left(\mathrm{J} \mathrm{kg}^{-1} \mathrm{~K}^{-1}\right)$ &
\end{tabular}




\begin{tabular}{|c|c|c|c|c|c|}
\hline$C_{q}$ & $\begin{array}{l}\text { Exchange coefficient depends on } \\
\text { atmospheric stability }\end{array}$ & Variable & $e_{a}$ & $\begin{array}{l}\text { Vapor pressure at reference } \\
\text { height }(\mathrm{hPa})\end{array}$ & Variable \\
\hline \multirow[t]{3}{*}{$C_{1}, C_{2}$} & $\begin{array}{l}\text { Coefficient used in the surface } \\
\text { soil moisture time dependent } \\
\text { equation } C_{1}=0.082\left(w_{\text {sat }} /\right.\end{array}$ & Variable & $e_{o}$ & $\begin{array}{l}\text { Aerodynamic vapor pressure } \\
\text { (hPa) at within-canopy source } \\
\text { height }\end{array}$ & Variable \\
\hline & $\begin{array}{l}\left.w_{g}\right)^{3.025} \text { and } C_{2}=3.9 w_{2} /\left(w_{\text {sat }}-\right. \\
\left.w_{2}+0.001\right),(\text { Noilhan and }\end{array}$ & & $e_{\text {sat }}(T)$ & $\begin{array}{l}\text { Saturated vapor pressure at tem- } \\
\text { perature } T(\mathrm{hPa})\end{array}$ & Variable \\
\hline & Planton 1989) & & $g_{\mathrm{s}}^{*}, g_{r}$ & Growth respiration coefficient for & Parameter \\
\hline$E_{g,} E_{\mathrm{tr}}$ & $\begin{array}{l}\text { Soil evaporation, plant transpira- } \\
\text { tion rates }\left(\mathrm{kg} \mathrm{m}^{-2} \mathrm{~s}^{-1}\right)\end{array}$ & Variable & & $\begin{array}{l}\text { shoots, roots }\left(0.6 \mathrm{gCO}_{2}\right. \\
\left.\mathrm{g}^{-1} \mathrm{DM}\right) \text { compartments }\end{array}$ & \\
\hline \multirow{3}{*}{$\begin{array}{l}G, H_{c}, H_{s} \\
\end{array}$} & Ground heat flux $\left(\mathrm{W} \mathrm{m}^{-2}\right)$ & Variable & \multirow[t]{2}{*}{$g_{s \max }$} & \multirow{2}{*}{$\begin{array}{l}\text { Maximum leaf stomatal conduc- } \\
\text { tance }\left(1 / r_{\text {smin }}=0.0078 \mathrm{~m} \mathrm{~s}^{-1}\right)\end{array}$} & \multirow[t]{2}{*}{ Parameter } \\
\hline & Total, canopy, soil sensible heat & Variable & & & \\
\hline & flux $\left(\mathrm{W} \mathrm{m}^{-2}\right)$ & & \multirow[t]{2}{*}{$h$, height } & \multirow{2}{*}{$\begin{array}{l}\text { Vegetation height }(\mathrm{cm}): 3.52+ \\
\quad 0.0073 M_{s}\left(\mathrm{kgC} \mathrm{ha}^{-1}\right)-0.000\end{array}$} & \multirow[t]{2}{*}{ Variable } \\
\hline LAI & Leaf area index $\left(\mathrm{m}^{2} \mathrm{~m}^{-2}\right)$ & Variable & & & \\
\hline $\mathrm{LE}, \mathrm{LE}_{c}, \mathrm{LE}_{s}$ & $\begin{array}{l}\text { Total, canopy, soil latent heat flux } \\
\left(\mathrm{W} \mathrm{m}^{-2}\right)\end{array}$ & Variable & \multirow[t]{2}{*}{$k$} & \multirow{2}{*}{$\begin{array}{l}\text { Von Kármán’s constant }(\sim 0.4, \\
\text { unitless })\end{array}$} & \multirow{2}{*}{ Constant } \\
\hline \multirow[t]{2}{*}{$M_{s,} M_{r,} M_{n}$} & Shoots biomass, roots biomass, & Variable & & & \\
\hline & $\begin{array}{l}\text { standing necromass }\left(\mathrm{kgC} \mathrm{m}^{-2}\right) \\
\text { Precipitation reaching the surface }\end{array}$ & Variable & $k_{e}$ & $\begin{array}{l}\text { Extinction coefficient for PAR ra- } \\
\text { diation }(0.5 \text {, unitless })\end{array}$ & Parameter \\
\hline$P$ & $\left(\mathrm{~kg} \mathrm{~m}^{-2} \mathrm{~s}^{-1}\right)$ & & \multirow[t]{2}{*}{$m_{s,} m_{r}$} & \multirow{2}{*}{$\begin{array}{l}\text { Rate of maintenance respiration } \\
\text { for shoots and roots }\end{array}$} & \multirow[t]{2}{*}{ Variable } \\
\hline \multirow[t]{2}{*}{$I$} & Photosynthetically active radia- & Variable & & & \\
\hline & $\begin{array}{l}\text { tion }\left(\mathrm{W} \mathrm{m}^{-2}\right) \\
\text { Initial carbon storage }\left(\mathrm{kgC} \mathrm{m}^{-2}\right)\end{array}$ & Parameter & \multirow[t]{2}{*}{$m_{s 0,} m_{r 0}$} & \multirow{2}{*}{$\begin{array}{l}\text { Maintenance respiration rate for } \\
\text { shoots }\left(0.003 \text { day }^{-1}\right) \text { and roots } \\
\left(0.0012 \text { day }^{-1}\right)\end{array}$} & Parameter \\
\hline$I_{o}$ & Incoming PAR at the top of the & Variable & & & \\
\hline & canopy $\left(\mathrm{W} \mathrm{m}^{-2}\right)$ & & $n$ & Attenuation coefficient of eddy & Parameter \\
\hline$I_{r}$ & $\begin{array}{l}\text { PAR level for which } r_{r} \text { equals } \\
2 r_{r \min }\end{array}$ & Parameter & & $\begin{array}{l}\text { diffusivity within the vegeta- } \\
\text { tion }(2.5 \text {, unitless })\end{array}$ & \\
\hline$I_{s}$ & $\begin{array}{l}\text { PAR level for stomata half-closure } \\
{\left[25 \mathrm{~W} \text { (PAR) } \mathrm{m}^{-2}\right]}\end{array}$ & Parameter & $n^{\prime}$ & $\begin{array}{l}\text { Attenuation coefficient of wind } \\
\text { speed within the vegetation }\end{array}$ & Parameter \\
\hline$P_{c}$ & Hourly canopy photosynthesis, & Variable & & (2.5, unitless) & \\
\hline & $\left(\mathrm{o} C \mathrm{~m}^{-2}\right)$ & & $r_{a a}$ & Aerodynamic resistance between & Variable \\
\hline$P_{\max }$ & $\begin{array}{l}\text { Maximum rate of leaf photosyn- } \\
\text { thesis }\left(30 \mu \mathrm{mol} \mathrm{CO} \mathrm{CO}^{-2} \mathrm{~s}^{-1}\right)\end{array}$ & Parameter & & $\begin{array}{l}\text { within-canopy source height } \\
\text { and above-canopy reference }\end{array}$ & \\
\hline$P_{l}$ & Leaf photosynthesis rate, $\left(\mathrm{gC} \mathrm{m}^{-2}\right.$ & Variable & & height $\left(\mathrm{s} \mathrm{m}^{-1}\right)$ & \\
\hline & $\left.\mathrm{s}^{-1}\right)$ & & $r_{a c}$ & Bulk boundary layer resistance of & Variable \\
\hline $\mathrm{Pn}$ & $\begin{array}{l}\text { Daily canopy photosynthesis ( } \mathrm{gC} \\
\mathrm{m}^{-2} \text { ) }\end{array}$ & Variable & $r_{a s}$ & $\begin{array}{l}\text { the canopy }\left(\mathrm{s} \mathrm{m}^{-1}\right) \\
\text { Aerodynamic resistance between }\end{array}$ & Variable \\
\hline$Q_{10}$ & $\begin{array}{l}\text { Ratio of the rate at one tempera- } \\
\text { ture to that at a temperature } \\
10^{\circ} \text { lower }\left(Q_{10}=2\right)\end{array}$ & Parameter & & $\begin{array}{l}\text { ground surface (soil source) } \\
\text { and within-canopy source } \\
\text { height }\left(\mathrm{s} \mathrm{m}^{-1}\right)\end{array}$ & \\
\hline $\mathrm{Rg}_{s}, \mathrm{Rg}_{r}$ & Shoots and roots growth respira- & Variable & $r_{c}$ & Canopy resistance $\left(\mathrm{s} \mathrm{m}^{-1}\right)$ & Variable \\
\hline & tion $\left(\mathrm{gC} \mathrm{m}^{-2}\right)$ & & $r_{r}$ & Leaf-level residual resistance & Variable \\
\hline $\mathrm{Rn}, \mathrm{Rn}_{c}, \mathrm{Rn}_{s}$ & Total, canopy, soil net radiation & Variable & & $\left(\mathrm{s} \mathrm{m}^{-1}\right)$ & \\
\hline SLA* & $\begin{array}{c}\left.(\mathrm{W} \mathrm{m})^{-2}\right) \\
\text { Specific leaf area at } M=0\left(\mathrm{~m}^{2}\right.\end{array}$ & Parameter & $r_{\text {min }}$ & $\begin{array}{l}\text { Minimum residual resistance } \\
\left(\sim 40 \mathrm{~s} \mathrm{~m}^{-1}\right) \text { to } C O \text { transfer }\end{array}$ & Parameter \\
\hline & $\left.\mathrm{kgC}^{-1}\right)$ & & $r_{s}$ & Leaf stomatal resistance $\left(\mathrm{s} \mathrm{m}^{-1}\right)$ & Variable \\
\hline$T_{a}$ & $\begin{array}{l}\text { Air temperature at reference } \\
\text { height }(\mathrm{K})\end{array}$ & Variable & $r_{\text {smin }}^{3}$ & $\begin{array}{l}\text { Minimum leaf stomatal resistance } \\
\qquad\left(128 \mathrm{~s} \mathrm{~m}^{-1}\right)\end{array}$ & Parameter \\
\hline$T_{c}$ & Temperature at canopy surface & Variable & $r_{\mathrm{ss}}$ & Soil surface resistance $\left(\mathrm{s} \mathrm{m}^{-1}\right)$ & Variable \\
\hline$T$ & $\begin{array}{l}\text { level }(\mathrm{K}) \\
\text { Ground surface temperature }(\mathrm{K})\end{array}$ & Variable & $s_{s,} s_{r}$ & $\begin{array}{l}\text { Rate of senescence for the shoots } \\
\text { and roots compartments }\end{array}$ & Variable \\
\hline$T_{o}$ & $\begin{array}{c}\text { Aerodynamic temperature }(\mathrm{K}) \text { at } \\
\text { within-canopy source height }\end{array}$ & Variable & $s_{s o}, s_{r \mathrm{o}}$ & $\begin{array}{l}\text { Mortality coefficient for shoots } \\
\left(0.01 \text { day }^{-1}\right) \text { and roots }(0.01\end{array}$ & Parameter \\
\hline$T_{\min }, T_{\max }$ & Minimum, maximum temperature & Parameter & & day $\left.^{-1}\right)$ & \\
\hline & $\begin{array}{l}\text { for photosynthesis }(283 \mathrm{~K} \text { and } \\
333 \mathrm{~K})\end{array}$ & & $u_{a}$ & $\begin{array}{l}\text { Wind speed at reference level } z_{\text {ref }} \\
\qquad\left(\mathrm{m} \mathrm{s}^{-1}\right)\end{array}$ & Variable \\
\hline$T_{r}$ & $\begin{array}{l}\text { Radiative or brightness tempera- } \\
\text { ture (emissivity is } 1)(\mathrm{K})\end{array}$ & Variable & $u_{h}$ & $\begin{array}{l}\text { Wind speed at the top of the can- } \\
\text { opy }\left(\mathrm{m} \mathrm{s}^{-1}\right)\end{array}$ & Variable \\
\hline Trans & Translocation of carbohydrates & Parameter & $u^{*}$ & Friction velocity $\left(\mathrm{m} \mathrm{s}^{-1}\right)$ & Variable \\
\hline & $\left(0.0004 \mathrm{kgC} \mathrm{m}^{-2}\right.$ day $\left.^{-1}\right)$ & & VPD & Vapor pressure deficit $(\mathrm{Pa})$ & Variable \\
\hline$a, b^{* *}$ & $\begin{array}{l}\text { Parameters for soil resistance pa- } \\
\text { rameterization }\left(r_{\mathrm{ss}}\right)\end{array}$ & Parameter & $w_{\mathrm{eq}}$ & $\begin{array}{l}\text { Surface soil moisture when gravi- } \\
\text { ty balances capillarity forces }\end{array}$ & Variable \\
\hline$a_{\mathrm{s}}^{*}$ & Coefficient for photosynthates al- & Parameter & & $\left(\mathrm{m}^{3} \mathrm{~m}^{-3}\right)$ & \\
\hline & $\begin{array}{l}\text { location to shoots compart- } \\
\text { ments }\end{array}$ & & $w_{\mathrm{fc}}$ & $\begin{array}{l}\text { Volumetric soil moisture at field } \\
\text { capacity }\left(0.14 \mathrm{~m}^{3} \mathrm{~m}^{-3}\right)\end{array}$ & Parameter \\
\hline$d$ & $\begin{array}{l}\text { Zero plane displacement height } \\
\text { for the canopy }(\mathrm{m})\end{array}$ & Variable & $w_{g}, w_{2}$ & $\begin{array}{l}\text { Volumetric soil moisture of the } \\
\text { surface layer, volumetric soil }\end{array}$ & Variable \\
\hline$d_{1}, d_{2}$ & $\begin{array}{l}\text { Depth of surface layer }(10 \mathrm{~cm}) \text {, } \\
\text { depth of the root zone }(60 \mathrm{~cm})\end{array}$ & Parameter & & $\begin{array}{l}\text { moisture of the root zone } \\
\left(\mathrm{m}^{3} \mathrm{~m}^{-3}\right)\end{array}$ & \\
\hline$d_{n}$ & $\begin{array}{l}\text { Rate of necromass decays (here, } \\
d_{n} \text { is set to } 0 \text { ) }\end{array}$ & Parameter & $w_{l}$ & $\begin{array}{l}\text { Characteristic leaf width } \\
(0.005 \mathrm{~m})\end{array}$ & Parameter \\
\hline
\end{tabular}




\begin{tabular}{|c|c|c|}
\hline$w_{\text {sat }}$ & $\begin{array}{l}\text { Soil moisture at saturation }[0.38 \\
\mathrm{m}^{3} \mathrm{~m}^{-3} \text {, estimated from soil } \\
\text { texture (clay }=6 \% \text { and sand } \\
=85 \%)]\end{array}$ & Parameter \\
\hline$w_{\mathrm{wp}}$ & $\begin{array}{l}\text { Volumetric soil moisture at wilt- } \\
\text { ing point }\left(0.036 \mathrm{~m}^{3} \mathrm{~m}^{-3}\right)\end{array}$ & Parameter \\
\hline$z_{\mathrm{o}}$ & $\begin{array}{l}\text { Roughness length of the canopy } \\
(\mathrm{m})\end{array}$ & Variable \\
\hline$z_{\mathrm{o}}^{\prime}$ & $\begin{array}{l}\text { Roughness length of the substrate } \\
\text { (m) }\end{array}$ & Variable \\
\hline$z_{\text {ref }}$ & $\begin{array}{l}\text { Reference height above the cano- } \\
\text { py where meteorological mea- } \\
\text { surements are available }(2 \mathrm{~m})\end{array}$ & Variable \\
\hline$\alpha^{*}$ & $\begin{array}{l}\text { Quantum yield }\left[\mu \mathrm{molCO}_{2}\right. \\
\left.\mu \mathrm{mol}(\mathrm{PAR})^{-1}\right]\end{array}$ & Parameter \\
\hline$\epsilon_{c,} \epsilon_{g}$ & $\begin{array}{l}\text { Canopy emissivity }(0.98) \text { and } \\
\text { ground surface emissivity } \\
(0.96)\end{array}$ & Parameter \\
\hline$\gamma$ & Psychrometric constant $\left(\mathrm{hPa} \mathrm{K}^{-1}\right)$ & Constant \\
\hline$\rho$ & Density of air $\left(\mathrm{kg} \mathrm{m}^{-3}\right)$ & Constant \\
\hline$\rho_{w}$ & Density of liquid water $\left(\mathrm{kg} \mathrm{m}^{-3}\right)$ & Constant \\
\hline$\sigma_{f}$ & $\begin{array}{l}\text { Screen factor (unitless), } \sigma_{f}=1 \\
\quad-\exp (-0.4 \mathrm{LAI})\end{array}$ & Variable \\
\hline$\tau$ & Time constant of one day (s) & Constant \\
\hline$\tau_{p}$ & SVAT time step $(3600 \mathrm{~s})$ & Constant \\
\hline
\end{tabular}

\section{APPENDIX C}

\section{SVAT Resistance Formulations}

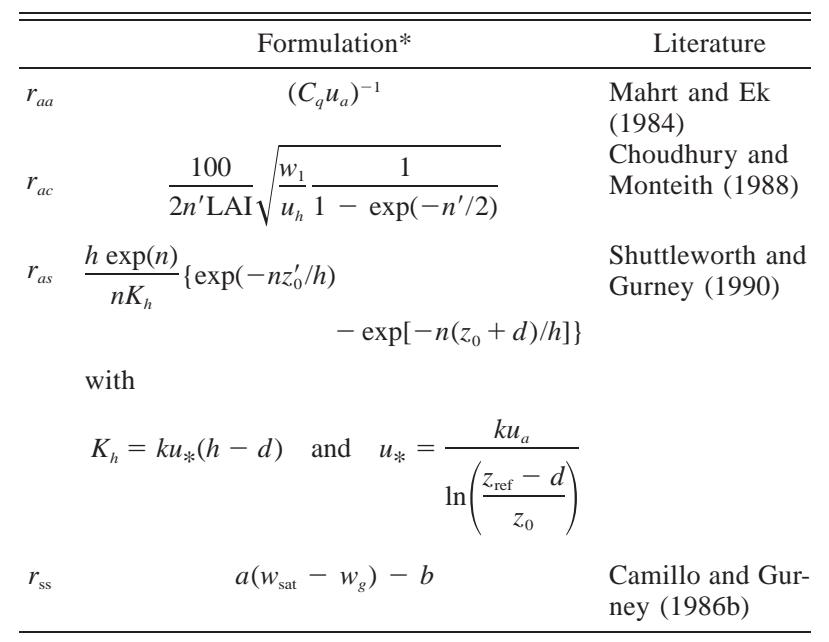

* All the symbols are defined in appendix B.

\section{REFERENCES}

Amthor, J. S., 1986: Evolution and applicability of a whole plant respiration model. J. Theor. Biol., 122, 473-490.

—_ 1989: Respiration and Crop Productivity. Springer-Verlag, 205 pp.

Andersen, H. S., 1997: Land surface temperature estimation based on NOAA-AVHRR data during the HAPEX-Sahel experiment. J. Hydrol., 188-189, 788-814.

Bouman, B. A. M., 1992: Growth models to simulate crop growth, optical reflectance, and radar backscatter of sugar beet and winter wheat, calibrated for Flevoland. Center for Agrobiological Research, Rep. 163.
Braud, I., P. Bessemoulin, B. Monteny, M. Sicot, J. P. Vandervaere, and M. Vauclin, 1997: Unidimensional modelling of a fallow savannah during HAPEX-Sahel experiment using the SiSPAT model. J. Hydrol., 188-189, 912-945.

Burke, E. J., R. J. Gurney, L. P. Simmonds, and T. J. Jackson, 1997: Calibrating a soil water and energy budget model with remotely sensed data to obtain quantitative information about the soil. Water Resour. Res., 33, 1689-1697.

Calvet, J. C., J. Noilhan, and P. Bessemoulin, 1998a: Retrieving the root-zone soil moisture or temperature estimates: A feasibility study based on field measurements. J. Appl. Meteor., 37, 371386.

$\longrightarrow,-$ J. L. Roujean, P. Bessemoulin, M. Cabelguenne, A. Olioso, and J. P. Wigneron, 1998b: An interactive vegetation SVAT model tested against data from six contrasting sites. Agric. For. Meteor., 92, 73-95.

Camillo, P. J., and R. J. Gurney, 1986a: A resistance parameter for bare soil evaporation models. Soil Sci., 141, 95-105.

— , P. E. O'Neill, and R. J. Gurney, 1986b: Estimating soil hydraulic parameters using passive microwave data. IEEE Trans. Geosci. Remote Sens., 24, 930-936.

Caselles, V., C. Coll, and E. Valor, 1997: Land surface emissivity and temperature determination in the whole HAPEX-Sahel area from AVHRR data. Int. J. Remote Sens., 18, 1009-1027.

Choudhury, B. J., and J. L. Monteith, 1988: A four layer model for the heat budget of homogeneous land surfaces. Quart. J. Roy. Meteor. Soc. Soc., 114, 373-398.

Deardorff, J. W., 1978: Efficient prediction of ground surface temperature and moisture, with inclusion of a layer of vegetation. J. Geophys. Res., 83, 1889-1903.

Delécolle, R., S. J. Maas, M. Guérif, and F. Baret, 1992: Remote sensing and crop production models. Present trends. ISPRS Photogramm. Remote Sens., 47, 145-161.

d'Herbés, J. M., and C. Valentin, 1997: Surface conditions of the Niamey region: Ecological and hydrological implications. J. Hydrol., 188-189, 18-42.

Dickinson, R. E., M. Shaikh, R. Bryant, and L. Graumlich, 1998: Interactive canopies for a climate model. J. Climate, 11, 28232836.

Dirmeyer, P. A., 1994: Vegetation stress as a feedback mechanism in midlatitude drought. J. Climate, 7, 1463-1483.

Entekhabi, D., H. Nakamura, and E. G. Njoku, 1994: Solving the inverse problem for soil moisture and temperature profiles by sequential assimilation of multifrequency remotely sensed observations. IEEE Trans. Geosci. Remote Sens., 32, 438-448.

Flerchinger, G. N., W. P. Kustas, and M. A. Weltz, 1998: Simulating surface energy fluxes and radiometric surface temperatures for two arid vegetation communities using the SHAW Model. $J$. Appl. Meteor., 37, 449-460.

Goel, N. S., 1988: Models of vegetation canopy reflectance and their use in estimation of biophysical parameters from reflectance data. Remote Sens. Rev., 4, 1-212.

Goutorbe, J P., and Coauthors, 1994: HAPEX-Sahel: A large scale of land-atmosphere interactions in the semiarid Tropics. Ann. Geophy., 12, 53-64.

Gupta, H. V., S. S. Sorooshian, and P. O. Yapo, 1998: Toward improved calibration of hydrologic models: Multiple and non commensurable measures of information. Water Resour. Res., 34, 751-763.

Hanan, N. P., A. Bégué, and S. D. Prince, 1997: Errors in remote sensing of intercepted photosynthetically active radiation: an example from HAPEX-Sahel. J. Hydrol., 188-189, 676-696.

Hollingsworth, A., 1990: Assimilation of remotely sensed atmospheric data from new satellite systems in the 1990s. Int. Symp. on Assimilation and Observations in Meteorology and Oceanography, Clermont-Ferrand, France, World Meteor. Org., 19-26.

Houser, P. A., W. J. Shuttleworth, J. S. Famiglietti, H. V. Gupta, K. H. Syed, and D. C. Goodrich, 1998: Integration of soil moisture remote sensing and hydrologic modeling using data assimilation. Water Resour. Res., 34, 3405-3420. 
Jarvis, P. G., 1976: The interpretation of the variations in the leaf water potential and stomatal conductance found in canopies in the field. Philos. Trans. Roy. Soc. London, 273B, 593-610.

Jones, A. S., I. C. Guch, and T. H. Vonder Haar, 1998a: Data assimilation of satellite-derived heating rates as proxy surface wetness data into a regional atmospheric meso-scale model. Part I: Methodology. Mon. Wea. Rev., 126, 634-645.

$\ldots,-1998$ b: Data assimilation of satellite-derived heating rates as proxy surface wetness data into a regional atmospheric mesoscale model. Part II: A case study. Mon. Wea. Rev., 126, 646-667.

Kergoat, L., 1998: A model for hydrological equilibrium of leaf area index on a global scale. J. Hydrol., 212-213, 268-286.

—, A. Fischer, S. Moulin, and G. Dedieu, 1995a: Satellite measurements as a constraint on estimates of vegetation carbon budget. Tellus, 47B, 251-263.

— of time series of satellite measurements in a vegetation model: Application to a humid Savannah site. Proc. Int. Colloq. on Photosynthesis and Remote Sensing. Montpellier, France, EARSeL-ISPRS, 457-464.

Kerr, Y. H., J. P. Lagouarde, and J. Imbernon, 1992: Accurate land surface temperature retrieval from AVHRR data with use of an improved Split Window Algorithm. Remote Sens. Environ., 41, 197-209.

—_ C. Guillou, J. P. Lagouarde, F. Nerry, and C. Ottle, 1998: World Land Surface Temperature Atlas-Algorithm Theoretical Basis Document. European Space Agency, CD-ROM.

_, T. Valéro, and S. Wagner, 1993: HAPEX-Sahel Information System, CD-ROM, disks 1 and 2. AVHRR 92, CESBIO.

- C. Guillou, J. P. Lagouarde, F. Nerry, and C. Ottlé, 1999: Algorithm theoretical basis document. LST Processor, Rep. 124 pp.

Körner, C., 1994, Leaf diffusive conductances in the major vegetation types of the globe. Ecophysiology of Photosynthesis, E. D. Schulze and M. M. Goldwell, Eds., Springer-Verlag, 463-490.

Kuusk, A., 1991: The inversion of the Nilson-Kuusk canopy reflectance model, a test case. Proc. Int. Geoscience and Remote Sensing Symp., Helsinki, Finland, IEEE, 1547-1550.

Lebel, T., H. Sauvageot, M. Hoepffner, M. Desbois, B. Guillot, and P. Hubert, 1992: Rainfall estimation in the Sahel: The EPSATNIGER experiment. Hydrol. Sci. J., 37, 201-215.

Le Roux, X., 1995: Étude et modelisation des échanges d'eau et d'énergie sol-vegetation-atmosphere dans une savanne humide (Lamto, Cote d'Ivoire) [Modelling water and energy cycles in a humid savannah (Lamto, Ivory Coast)]. Thèse del'Université Pierre et Marie Curie, 203 pp. [Available from Université Pierre et Marie Curie, Paris, France.]

Levy, P. E., J. B. Moncrieff, J. M. Massheder, P. G. Jarvis, S. L. Scott, and J. Brouwer, 1997: $\mathrm{CO}_{2}$ fluxes at leaf and canopy scale in millet, fallow and tiger bush vegetation at the HAPEX-Sahel southern super site. J. Hydrol., 188-189, 612-632.

Lloyd, C. R., and Coauthors, 1997: Comparison of surface fluxes a the HAPEX-Sahel Fallow bush sites. J. Hydrol., 188-189, 400425.

Lo Seen, D., E. Mougin, S. Rambal, A. Gaston, and P. Hiernaux, 1995: A regional Sahelien grassland model to be coupled with multispectral satellite data. II: Toward the control of its simulations by remotely sensed Indices. Remote Sens. Environ., 52, 194-206.

—, A. Chehbouni, E. G. Njoku, S. Saatchi, E. Mougin, and B. Monteny, 1997: A coupled biomass production, water and surface energy balance model for remote sensing application in semiarid grasslands. Agric. For. Meteor., 83, 49-74.

Maas, S. J., 1991: Use of remotely sensed information in plant growth simulation models. Adv. Agron., 1, 17-26.

Mahrt, L., and M. Ek, 1984: The influence of atmospheric stability on potentiel evaporation. J. Climate. Appl. Meteor., 23, 222234.

Mattikalli, N. M., E. T. Engman, T. J. Jackson, and L. R. Ahuja, 1998: Microwave remote sensing of temporal variations of brightness temperature and near-surface soil water content during a watershed-scale field experiment, and its application to the estimation of soil physical properties. Water Resour. Res., 34, 2289-2299.

McCree, K. J., 1970: An equation for the rate of respiration of white clover plants grown under controlled conditions. Prediction and Measurement of Photosynthetic Productivity, I. Setlik, Ed., PUDOC, 221-229

Moncrieff, J. B., and Coauthors, 1997: Spatial and temporal variations in net carbon flux during HAPEX-Sahel. J. Hydrol., 188-189, 563-588.

Monteith, J. L., 1975: Vegetation and the Atmosphere. Academic Press $278 \mathrm{pp}$

Monteny, B. A., and Coauthors, 1997: The role of the Sahelian biosphere on the water and the $\mathrm{CO} 2$ cycle during the HAPEX-Sahel Experiment. J. Hydrol., 188-189, 516-535.

Mougin, E., D. Lo Seen, S. Rambal, A. Gaston, and P. Hiernaux, 1995: A regional sahelien grassland model to be coupled with satellite multispectral data. I. Validation. Remote Sens. Environ., 52, 181-193.

Moulin, S., L. Kergoat, N. Viovy, and G. Dedieu, 1997: Global scale assessment of vegetation phenology using NOAA/AVHRR satellite measurements. J. Climate, 10, 1154-1170.

- A. Bondeau, and R. Delécolle, 1998: Combining agricultural crop models and satellite observations: From field to regional scales. Int. J. Remote Sens., 19, 1021-1036.

Noilhan, J., and S. Planton, 1989: A simple parametrization of land surface processes for meteorological models. Mon. Wea. Rev. 117, 536-549.

Nouvellon, Y., 1999: Modélisation du fonctionnement de prairies semi-arides et assimilation de données radiométriques dans le modèle. (Assimilation of remotely sensed data into a model of semi-arid grasslands). Thèse de l'Institut National Agronomique, $123 \mathrm{pp}$.

Olioso, A., H. Chauki, D. Courault, and J. P. Wigneron 1999: Estimation of evapotranspiration and photosynthesis by assimilation of remote sensing data into SVAT models. Remote Sens. Environ., 68, 341-356.

Ottlé, C., and D. Vidal-Madjar, 1993: Assimilation of soil moisture inversed from infrared remote sensing in a hydrological model over the Hapex-Mobilhy region. J. Hydrol., 158, 241-264.

Ouaidrari, H., A. Bégué, J. Imbernon, and J. D’Herbes, 1996: Extraction of the pure spectral response of the landscape components in NOAA-AVHRR mixed pixels-Application to the HAPEX-Sahel degree square. Int. J. Remote Sens., 17, 22592280.

Pielke, R. A., and R. Avissar, 1990. Influence of landscape structure on local and regional climate. Landscape Ecol., 4, 133-155.

, G. E. Liston, L. Lu, P. L. Vidale, R. L. Walko, T. G. F. Kittel, W. J. Parton, and C. B. Field, 1997: Coupling of land and atmospheric models over the GCIP area-Century, RAMS, and SIB2C. Preprints, 13th Conf. on Hydrology, Long Beach, CA, Amer. Meteor. Soc., 92-96.

Prince, S. D., and Coauthors, 1995: Geographical, biological, and remote sensing aspects of the Hydrologic Atmospheric Pilot Experiment in the Sahel (HAPEX-Sahel). Remote Sens. Environ., 51, 215-234.

Rahman, H., and G. Dedieu, 1994: SMAC: A simplified method for the atmospheric corrections of satellite measurements in the solar spectrum. Int. J. Remote Sens., 15, 123-143.

Rouse, J. W., R. H. Haas, J. A. Schell, D. W. Deering, and J. C. Harlan, 1974: Monitoring the vernal advancement and retrogradation of natural vegetation. NASA/GSFC Final Rep., 371 pp.

Running, S. W., and J. C. Coughlan, 1988: A global model of forest ecosystem processes for regional applications. Hydrological balance canopy gas exchange and primary production processes. Ecol. Modell., 42, 125-154.

Saugier, B., and N. Katerji, 1991: Some plant factors controlling evapotranspiration. Agric. For. Meteor., 54, 263-277.

Schmugge, T. J., and G. M. Schmidt, 1998: Surface Temperature 
Observations from AVHRR in FIFE. J. Atmos. Sci., 55, 12391246.

Sellers, P. J., 1986: Simple biosphere model $(\mathrm{SiB})$ for use within general circulation models. J. Atmos. Sci, 43, 505-531.

Shuttleworth, W. J., and J. S. Wallace, 1985: Evaporation from sparse crops an energy combination theory. Quart. J. Roy. Meteor. Soc., 111, 839-855.

— , and R. J. Gurney, 1990: The theoretical relationship between foliage temperature and canopy resistance in parse crops. Quart. J. Roy. Meteor. Soc., 116, 497-519.

Spitters, C. J. T., H. van Keulen, and D. W. G. van Kraalingen, 1989: A simple and universal crop growth simulator: SUCROS87. Simulation and System Management in Crop Protection, R. Rabbinge, S. A. Ward, and H. H. van Laar, Eds., PUDOC, 147-181.

Taconet, O., R. Bernard, and D. Vidal-Madjar, 1986: Evapotranspiration over an agricultural region using a surface flux/temperature model based on NOAA-AVHRR data. J. Climate Appl. Meteor., 25, 284-307.
Tucker, J. C., 1979: Red and photographic infrared linear combinations for monitoring vegetation. Int. J. Remote Sens., 8, 127150.

van de Griend, A. A., M. Owe, M. Groen, and M. P. Stoll, 1991: Measurements and spatial variation of thermal infrared surface emissivity in a savanna environment. Water Resour. Res., 27, 371-379.

van Leeuwen, W. J. D., A. R. Huete, C. L. Walthall, S. D. Prince, A. Bégué, and J. L. Roujean, 1997: Deconvolution of remotely sensed spectral mixtures for retrieval of LAI, fAPAR and soil brightness. J. Hydrol., 188-189, 697-724.

Verhoef, W., 1984: Light scattering by leaf layers with application to canopy reflectance modeling: The SAIL model. Remote Sens. Environ., 16, 125-141.

Zhihao, Q., and A. Karnieli, 1999: Progress in remote sensing of land surface temperature and ground emissivity using NOAAAVHRR data. Int. J. Remote Sens., 20, 2367-2393. 